Effects of ambient versus reduced UV-B radiation on high arctic Salix arctica assessed by measurements and calculations of chlorophyll-a fluorescence parameters from fluorescence transients

\title{
Albert, Kristian Rost
}

Published in:

Physiologia Plantarum

Publication date:

2005

Document Version

Publisher's PDF, also known as Version of record

Link back to DTU Orbit

Citation $(A P A)$ :

Albert, K. R. (2005). Effects of ambient versus reduced UV-B radiation on high arctic Salix arctica assessed by measurements and calculations of chlorophyll-a fluorescence parameters from fluorescence transients. Physiologia Plantarum, 124, 208-226.

\section{General rights}

Copyright and moral rights for the publications made accessible in the public portal are retained by the authors and/or other copyright owners and it is a condition of accessing publications that users recognise and abide by the legal requirements associated with these rights.

- Users may download and print one copy of any publication from the public portal for the purpose of private study or research.

- You may not further distribute the material or use it for any profit-making activity or commercial gain

- You may freely distribute the URL identifying the publication in the public portal 


\title{
Effects of ambient versus reduced UV-B radiation on high arctic Salix arctica assessed by measurements and calculations of chlorophyll a fluorescence parameters from fluorescence transients
}

\author{
Kristian R. Albert ${ }^{\mathrm{a}, *}$, Teis N. Mikkelsen ${ }^{\mathrm{b}}$ and Helge Ro-Poulsen ${ }^{\mathrm{a}}$ \\ ${ }^{a}$ Department of Terrestrial Ecology, Biological Institute, University of Copenhagen, Øster Farimagsgade 2D, DK-1353 Copenhagen K, Denmark \\ ${ }^{b}$ Biosystems Research, Risø National Laboratory, DK-4000 Roskilde, Denmark
}

\author{
Correspondence \\ *Corresponding author, \\ e-mail: kristiana@bi.ku.dk \\ Received 18 November 2004; revised \\ 17 January 2005
}

doi: 10.1111/j.1399-3054.2005.00502.x
A UV-B exclusion-experiment was conducted in the high Arctic Zackenberg, NE Greenland, in which Salix arctica leaves during most of the growing season were fixed perpendicular to the solar zenith angle, thereby receiving maximal solar radiation. Covered with Teflon and Mylar foil, the leaves received approximately 90 and $40 \%$ of the ambient UV-B irradiance, respectively. The effects were examined through recordings of chlorophyll a fluorescence transients, determination of biomass and analysis of total carbon and nitrogen content and amount of soluble flavonoids in the leaves. The processing of light was analysed by means of the chlorophyll a fluorescence transient, using the so-called JIP test, as evolved by Reto J. Strasser and his coworkers. Reduction of the UV-B irradiance caused a rise in many of the fluorescence parameters during July, but not in August (late season). Thus increases in the efficiency that an absorbed photon will be trapped by the PSII reaction centre with the resultant reduction of $\mathrm{Q}_{\mathrm{A}}$ to $\mathrm{Q}_{\mathrm{A}}{ }^{-}\left(\mathrm{ET}_{0} / \mathrm{ABS}=\mathrm{F}_{\mathrm{V}} / \mathrm{F}_{\mathrm{M}}\right)$ and the efficiency that an electron residing on $\mathrm{Q}_{\mathrm{A}}{ }^{-}$will enter the intersystem electron transport chain $\left(\mathrm{ET}_{0} / \mathrm{TR}_{0}\right)$ were observed in reduced UV-B. Moreover, estimated per cross-section of leaf sample, the number of active PSII reaction centres (RC/ $\left.\mathrm{CS}_{M}\right)$ and electron transport rate $\left(\mathrm{ET}_{M} / \mathrm{CS}_{M}\right)$ and all performance indexes $\left(\mathrm{PI}_{\mathrm{ABS}}\right.$, $\mathrm{PI}_{\mathrm{CSo}}$ and $\mathrm{PI}_{\mathrm{CSm}}$ ) were increased in reduced UV-B. The total soluble flavonoid content was highest in ambient UV-B. The treatment effects on fluorescence parameters that were directly measured (e.g. $\mathrm{F}_{0}$ and $\mathrm{F}_{\mathrm{M}}$ ) and those that were derived (e.g. quantum efficiencies, parameters per PSII reaction centres and per cross-section of leaf sample) are discussed in relation to one another, in relation to daily and seasonal variation, and from the perspective of evaluating the relative importance of UV-B of donor and acceptor side capacity in Photosystem II. In conclusion, the experimental set-up and non-invasive measurements proved to be a sensitive method to screen for effects of UV-B stress.

\footnotetext{
Abbreviations - D1, core subunit of PSII; JIP test, analysis of parameters derived from the fluorescence transient (see Table 1); Mn cluster, four ion cluster which is a part of OEC going through five redox states during water splitting; OEC, oxygen evolving complex extracting electrons from water; PSI, Photosystem I; PSII, Photosystem II; $\mathrm{Q}_{\mathrm{A}}$, Plastoquinone A carrier of electrons from P680; $\mathrm{Q}_{\mathrm{B}}$, Plastoquinone $\mathrm{B}$ carrier of electrons from $\mathrm{Q}_{\mathrm{A}} ; \mathrm{Tyr}$, secondary electron donor residue on D1 between OEC and P680; P680, the specialized chlorophyll reaction centre in PSII.
} 


\section{Introduction}

High Arctic plants live at the limit of their distribution in an extreme environment with a short growing season, low temperature, and often nutrient limitation. Additional stress may therefore be crucial (Björn et al. 1999). Stratospheric ozone depletion increases the amount of UV-B (280-320 nm) reaching the surface of the earth (Farman et al. 1985, Webb 1997, Madronich et al. 1998), the relative increase in UV-B being largest at the higher latitudes (Björn et al. 1999). Plants in high latitude ecosystems are adapted to low UV-B levels and it is therefore expected that high latitude ecosystems are susceptible to UV-B (Caldwell et al. 1980, Robberecht et al. 1980). After many indoor studies conducted in unrealistically low background UV-A (315-400 nm) and PAR (400-700 nm) that could exaggerate UV-B response (Caldwell and Flint 1994, 1997, Caldwell et al. 1994), field experiments, in which UV-B has been increased with lamps or reduced with filters, have been published (Caldwell and Flint 1997, Caldwell et al. 1998, Paul 2001, Flint et al. 2003, Paul and Gwynn-Jones 2003). In this broad context, a growing number of studies have addressed effects on Arctic (Gehrke et al. 1996, Gwynn-Jones and Johanson 1996, Gwynn-Jones et al. 1997, Björn et al. 1999, Bredahl et al. 2004) and Antarctic ecosystems (Robson et al. 2003, Day et al. 2001, Rousseaux et al. 2001, Xiong and Day 2001). However, no one has evaluated these effects on PSII in the photosynthetic apparatus by screening leaves with chlorophyll-a fluorescence measurements, and analysing them with the so-called JIP test (Strasser et al. 2000, 2004).

Excess light can result in imbalance between the energy absorbed through the light harvesting complex and the amount of energy that can be dissipated or transduced by PSII and PSI. Such imbalance may be generated by excess light alone or may be enhanced by biotic and abiotic stress factors resulting in excess excitation energy (Bilger and Björkman 1991, Strid et al. 1996, Karpinski et al. 2001). Dissipation of excess energy is an immediate response which occurs mainly through heat dissipation (Demig-Adams and Adams 1994, Krause 1994) and detectable with the JIP test. In case of prolonged exposure to conditions causing excess light excitation, reactive oxygen species are potential photodamaging agents if the accumulation of excess light energy exceeds the capacity of antioxidant systems (Karpinski et al. 1997, 1999, 2001, Asada 1999, Mullineaux et al. 2000) and precede down-regulation of photosynthesis (Mackerness et al. 1998, Krause 1994b).

Many studies have identified PSII as the most labile component of the photosynthetic apparatus to elevated
UV-B radiation (Iwanzik et al. 1983, Strid et al. 1990, Melis et al. 1992, Vass et al. 1996, Mackerness et al. 1997, Jansen et al. 1998), but the underlying mechanisms are still a controversial subject (Andersson and Aro 2001). Both donor side mechanisms at the level of the water splitting system and/or $\mathrm{Tyr}_{\mathrm{d}}$ and $\mathrm{Tyr}_{\mathrm{z}}$ (Renger et al. 1989, Vass et al. 1996, Larkum et al. 2001) and acceptor side mechanisms have been reported (Jansen et al. 1996, 1998). From simultaneous monitoring of both donor and acceptor mechanisms, it could be concluded that UV-B light impairs both electron transfer from the $\mathrm{Mn}$ water oxidation cluster to $\mathrm{Tyr}_{\mathrm{z}}{ }^{+}$and $\mathrm{P}_{680^{+}}$as well as acceptor side modifications, particularly in the $\mathrm{Q}_{\mathrm{B}}$ pocket of the D1 protein (Vass et al. 1999). Since the full kinetics from O-step to P-step include contributions of several reaction mechanisms (Strasser et al. 2004), then the analysis of derived parameters, such as the overall grouping probability or energetic co-operativity (Stirbet et al. 1998), approximated fraction of non- $Q_{B}$ reducing units which relates to heterogeneity concerning the $\mathrm{Q}_{\mathrm{A}}-\mathrm{Q}_{\mathrm{B}}$ binding (see discussion by Strasser et al. 2004), but also the step at $300 \mu$ s (K-band) related to the oxygen-evolving complex (OEC) (see discussion by Strasser et al. 2004), which are related to donor and acceptor side of PSII, it is possible that extensive analysis and/or application of the JIP test may contribute to this subject.

This study focuses on PAR and UV-B effects on the light processing through PSII in Salix arctica leaves in the high arctic. The experimental approach chosen was to reduce the UV-B irradiance by means of filters. In an earlier study (Bredahl et al. 2004), a large variation in $\mathrm{F}_{\mathrm{V}} / \mathrm{F}_{\mathrm{M}}$ measurements was observed, which was partly supposed to be associated with the large variation in leaf orientation towards the sun. Thus, we conducted an experiment where the leaves were fixed in a position exposing them to maximum solar irradiance. The processing of light through PSII was analysed by means of recording transients of chlorophyll a fluorescence, and analysing it using the JIP test and associated parameters (Krause and Weis 1991, Strasser and Strasser 1995, Strasser et al. 1995, Krüger et al. 1997, Strasser et al. 2000, 2004), a methodology discussed by Lazár (1999) and recently by Force et al. (2003).

\section{Materials and methods}

\section{Experimental site}

The fieldwork was carried out in a high arctic heathland at Zackenberg Research Station, North-east Greenland $\left(74^{\circ} \mathrm{eN}, 21^{\circ} \mathrm{E}\right)$ in July and August of 2002. 
The plant species investigated was the abundantly occurring Salix arctica Pall. Lge. (Böcher et al. 1978), having a robust stem and broad leaves well suited for the manipulations and measurements.

\section{Experimental set-up and treatments}

Experimental plots were established where parts of the UV-irradiance in natural daylight were reduced with ambient UV-B irradiance as reference. Reduction was achieved by filtering the solar radiation through a filter, Mylar $^{\circledR}$. (type D; DuPont Teijin Films, Wilmington, DE). Mylar filter transmits $\lambda>320 \mathrm{~nm}$ (Cybulski and Peterjohn 1999). As control, a Teflon ${ }^{\circledR}$. filter (Fluoretek AB, Knivsta, Sweden.) was used. None of these filters have phytotoxic effects, as reported for cellulose diacetate (Krizek and Mirecki 2004). Teflon transmits $\lambda>280 \mathrm{~nm}$ (Cybulski and Peterjohn 1999). Measurements in the experimental area with a broad-band cosine corrected UV-B sensor (UV-S-310-T, Scintec; Atmosphärenmesstechnik GmbH, Tübingen, Germany - now manufactured as UV-S-B-T from Kipp \& Zonen B.V., Delft, The Netherlands) showed that the plant canopy under Teflon and Mylar was exposed to approximately 91 and 39\% of the clear sky UV-B irradiance, respectively, slightly depending on the exposure angle to the sun (Bredahl et al. 2004). In the following, the Teflon cover is referred to as 'ambient UV-B' and Mylar cover as 'reduced UV-B'.

Nylon strings were used to fix plant-shoots and leaves, to rectangular aluminium frames. Each frame was forced into the soil just in front of a Salix plant base. Then one long $(10-20 \mathrm{~cm})$ shoot was carefully fixed in a way so that all leaf surfaces were exposed in an angle of $45^{\circ}$ facing south. Then the filter sheets were fastened to the frames with clamps. This set-up was used to expose the plants to maximum PAR and UV-B and allowed easy access to measurements.

The experiment was designed as a randomized design where each treatment consisted of 20 shoots from different plant individuals, in total 40 shoots.

\section{Light regime}

Climatic data were recorded at two nearby experimental sites and at the permanent climate station on Zackenberg throughout the season. PAR was measured with one sensor placed horizontally and maximum PAR by another sensor inclined at $45^{\circ}$ to the south (GaAsP photodiode, Pontailler 1990). UV-B was measured by means of a horizontally mounted broad-band cosinecorrected sensor (UV-S-B-T/C; Kipp \& Zonen, Delft, The Netherlands). The sensors were connected to dataloggers (CR 10X; Campbell Scientific, Ltd, Loughborough, UK) and hourly means of UV-B and PAR were recorded as the average of per minute recordings.

\section{Chlorophyll a fluorescence}

During July 6 to August 20, 2002, transients of chlorophyll a fluorescence were measured approximately every third day at $1430 \mathrm{~h}$ on Salix arctica. On 1, 6 and 13 August measurements were conducted at 0900, 1400 and $1800 \mathrm{~h}$ to investigate daily variations. After removal of the filter cover, a dark adaptation clip was mounted for 35-40 min on one of the exposed leaves to ensure that all PSII were in the dark-adapted state with open RC. The mounting of clips on all plants took less than $10 \mathrm{~min}$. Then chlorophyll a fluorescence transients were recorded and digitized with a portable Handy PEA (Hansatech Instruments, Ltd. King's Lynn Norfolk, UK) with a 12-bit resolution from $10 \mu \mathrm{s}$ to $1 \mathrm{~s}$ and a time resolution of $10 \mu \mathrm{s}$ for the first 200 data points (Strasser et al. 1995). The excitation light intensity was $600 \mathrm{~W} \mathrm{~m}^{-2}$ from an array of six red light-emitting diodes with a peak wavelength at $650 \mathrm{~nm}$ focused on the leaf surface in the clips on a spot of $4 \mathrm{~mm}$ in diameter. The chlorophyll a fluorescence signals were detected by the Handy Pea using a PIN photocell after having passed through a long pass filter (50\% transmission at $720 \mathrm{~nm})$ (Srivastava et al. 1997). The measurements were always done in the same order, alternating between different treatments. Initial measurements were done on 6 July 2002, on the plants after their fixation, but before attachment of filters. Afterwards, the filters were permanently attached and removed only when the measurements were conducted.

\section{Analysis of fluorescence: the JIP test}

From the fluorescence transient, the measured parameters $\left(F_{0}, F_{M}, t_{M}\right.$, Area, $\left.F_{50 \mu s}, F_{100 \mu s}, F_{300 \mu s}, F_{J}, F_{l}\right)$ led to calculation and derivation of a range of new parameters according to Strasser et al. (2000, 2004) (see Table 1). Careful translation of the measured parameters into JIP test parameters provides information of the stepwise flow of energy through PSII at different levels: (1) specific fluxes on the level per reaction centre $(\mathrm{RC})$ and these are for absorption $(\mathrm{ABS} / \mathrm{RC})$, trapping $\left(\mathrm{TR}_{0} / \mathrm{RC}\right)$, dissipation $\left(\mathrm{DI}_{0} / \mathrm{RC}\right)$ and electron transport $\mathrm{ET}_{0} / \mathrm{RC}$ ); and (2) phenomenological fluxes on the level of the excited sample cross-section (CS) and these are for absorption $(\mathrm{ABS} / \mathrm{CS})$, trapping $\left(\mathrm{TR}_{0} / \mathrm{CS}\right)$, dissipation $\left(\mathrm{DI}_{\mathrm{O}} / \mathrm{CS}\right)$ and electron transport $\left(\mathrm{ET}_{\mathrm{O}} / \mathrm{CS}\right)$ (Table 1$)$. By assuming that $F_{0}$ and $F_{M}$ are reasonable measures of 
Table 1. Summary of parameters, formulae and their description using data extracted from the fast fluorescence transient O-J-I-P. ABS, absorption energy flux; CS, excited cross-section of leaf sample; DI, dissipation energy flux at the level of the antenna chlorophylls; $E$, flux of electrons from $\mathrm{Q}_{A}^{-}$ into the intersystem electron transport chain; $\varphi_{\text {Po }}$ maximal quantum yield of primary photochemistry; $\psi_{0}$, efficiency by which a trapped exciton, having triggered the reduction of $\mathrm{Q}_{\mathrm{A}}$ to $\mathrm{Q}_{\mathrm{A}}{ }^{-}$, can move an electron further than $\mathrm{Q}_{\mathrm{A}}{ }^{-}$into the electron transport chain; $\mathrm{RC}, \mathrm{PS} \| \mathrm{r}$ reaction centre; $\mathrm{RC} / \mathrm{CS}$, concentration of reaction centres per excited cross-section of leaf sample; TR, excitation energy flux trapped by a RC and utilized for the reduction of $\mathrm{Q}_{\mathrm{A}}$ to $\mathrm{Q}_{\mathrm{A}}^{-} ; \mathrm{Pl}$, performance index. Note the distinction between measured and derived parameters. Adapted and reorganized from Strasser et al. (2000) and Strasser et al. (2004).

\begin{tabular}{|c|c|}
\hline \multicolumn{2}{|c|}{ Extracted and technical fluorescence parameters } \\
\hline \multicolumn{2}{|c|}{ Measured parameters } \\
\hline $\mathrm{F}_{0}$ & Initial fluorescence intensity \\
\hline $\mathrm{F}_{\mathrm{M}}$ & Maximal fluorescence intensity \\
\hline $\mathrm{F}_{50 \mu \mathrm{s}}$ & Fluorescence intensity at $50 \mu \mathrm{s}$ \\
\hline $\mathrm{F}_{100 \mu \mathrm{s}}$ & Fluorescence intensity at $100 \mu \mathrm{s}$ \\
\hline$F_{300 \mu s}$ & Fluorescence intensity at $300 \mu \mathrm{s}$ \\
\hline$F_{J}$ & Fluorescence intensity at the J-step (at 2 ms) \\
\hline $\mathrm{F}_{1}$ & Fluorescence intensity at the I-step (at $30 \mathrm{~ms}$ ) \\
\hline Area & Area between fluorescence curve and $F_{M}$ \\
\hline $\mathrm{tFm}$ & Time to reach $F_{M}$ in $m s$ \\
\hline \multicolumn{2}{|c|}{ Derived parameters } \\
\hline \multicolumn{2}{|c|}{ Selected J-I-P-parameters } \\
\hline $\mathrm{F}_{\mathrm{V}}$ & $\left(F_{M}-F_{0}\right)$ \\
\hline $\mathrm{F}_{\mathrm{V}} / \mathrm{F}_{\mathrm{M}}$ & $\left(F_{M}-F_{0}\right) / F_{M}$ \\
\hline$v_{J}$ & $\left(F_{J}-F_{0}\right) /\left(F_{M}-F_{0}\right)$ \\
\hline$V_{1}$ & $\left(F_{1}-F_{0}\right) /\left(F_{M}-F_{0}\right)$ \\
\hline Sm & Area $/\left(F_{M}-F_{0}\right)$ \\
\hline $\mathrm{N}$ & $\mathrm{Sm} *\left(\mathrm{M}_{0} \mathrm{~N}_{\mathrm{J}}\right)$ \\
\hline$(\mathrm{dV} / \mathrm{dt})_{0}=\mathrm{M}_{0}$ & $4 *\left(F_{300 \mu s}-F_{0}\right) /\left(F_{M}-F_{0}\right)$ \\
\hline Yield $P_{J}$ & $1-\left(F_{J} / F_{M}\right)$ \\
\hline Yield $P_{1}$ & $1-\left(F_{1} / F_{M}\right)$ \\
\hline Yield $P_{0}$ & $\mathrm{~F}_{\mathrm{V}} / \mathrm{F}_{\mathrm{M}}$ \\
\hline$F_{J} / F_{0}$ & $\mathrm{~F}_{\mathrm{J}} / \mathrm{F}_{0}$ \\
\hline$F_{1} / F_{0}$ & $F_{1} / F_{0}$ \\
\hline $\mathrm{F}_{\mathrm{M}} / \mathrm{F}_{0}$ & $\mathrm{~F}_{\mathrm{M}} / \mathrm{F}_{0}$ \\
\hline \multicolumn{2}{|c|}{ Quantum efficiencies } \\
\hline$\phi_{\mathrm{Po}}=\mathrm{TR}_{0} / \mathrm{ABS}$ & $\mathrm{F}_{\mathrm{V}} / \mathrm{F}_{\mathrm{M}}$ \\
\hline$\phi_{\mathrm{Eo}}=\mathrm{ET} / \mathrm{ABS}$ & $\mathrm{F}_{\mathrm{V}} / \mathrm{F}_{\mathrm{M}} *\left(1-\mathrm{V}_{\mathrm{J}}\right)$ \\
\hline$\varphi_{\mathrm{o}}=\mathrm{ET}_{0} / \mathrm{TR}_{0}$ & $\left(1-V_{J}\right)$ \\
\hline \multicolumn{2}{|l|}{ Specific fluxes } \\
\hline $\mathrm{ABS} / \mathrm{RC}$ & $\mathrm{M}_{0} *\left(1 \mathrm{~N}_{\mathrm{J}}\right) *\left(1 / \phi_{\mathrm{Po}}\right)$ \\
\hline $\mathrm{TR}_{0} / \mathrm{RC}$ & $\mathrm{M}_{0} *\left(1 \mathrm{~N}_{\mathrm{J}}\right)$ \\
\hline $\mathrm{ET}_{0} / \mathrm{RC}$ & $\mathrm{M}_{0} *\left(1 \mathrm{~N}_{\mathrm{J}}\right) * \varphi_{\mathrm{o}}$ \\
\hline $\mathrm{DI}_{0} / \mathrm{RC}$ & $(A B S / R C)-\left(T R_{0} / R C\right)$ \\
\hline \multicolumn{2}{|c|}{ Phenomenological fluxes } \\
\hline $\mathrm{ABS} / \mathrm{CS}$ & $\mathrm{ABS} / \mathrm{CS}_{\mathrm{Chl}}=\mathrm{Chl} / \mathrm{CS}$ or $\mathrm{ABS} / \mathrm{CS}_{0}=\mathrm{F}_{0}$ or $\mathrm{ABS} / \mathrm{CS}_{\mathrm{M}}=\mathrm{F}_{\mathrm{M}}$ \\
\hline $\mathrm{TR}_{0} / \mathrm{CS}_{0}$ & $\mathrm{ABS} / \mathrm{CS}_{0} * \phi_{\mathrm{PO}}$ \\
\hline $\mathrm{ET}_{0} / \mathrm{CS}_{0}$ & $\mathrm{ABS} / \mathrm{CS}_{0} * \phi_{\mathrm{PO}} * \varphi_{\mathrm{O}}$ \\
\hline $\mathrm{DI}_{0} / \mathrm{CS}_{0}$ & $\left(A B S / C S_{0}\right)-\left(T_{0} / C S_{0}\right)$ \\
\hline $\mathrm{TR}_{\mathrm{M}} / \mathrm{CS}_{\mathrm{M}}$ & $\mathrm{ABS} / \mathrm{CS}_{\mathrm{M}} * \phi_{\mathrm{PO}}$ \\
\hline$E \mathrm{~T}_{\mathrm{M}} / \mathrm{CS}_{\mathrm{M}}$ & $\mathrm{ABS} / \mathrm{CS}_{\mathrm{M}} * \phi_{\mathrm{Po}} * \varphi_{\mathrm{O}}$ \\
\hline $\mathrm{DI}_{\mathrm{M}} / \mathrm{CS}_{\mathrm{M}}$ & $\left(A B S / C S_{M}\right)-\left(T R_{0} / C S_{0}\right)$ \\
\hline \multicolumn{2}{|c|}{ Density of PSII reaction centre } \\
\hline $\mathrm{RC} / \mathrm{CS}_{0}$ & $\phi_{\mathrm{Po}} *\left(\mathrm{~V}_{\mathrm{J}} / \mathrm{M}_{0}\right) * \mathrm{ABS} / \mathrm{CS}_{0}$ \\
\hline $\mathrm{RC} / \mathrm{CS}_{\mathrm{M}}$ & $\phi_{\mathrm{Po}} *\left(V_{\mathrm{J}} / \mathrm{M}_{0}\right) * A B S / C S_{\mathrm{M}}$ \\
\hline \multicolumn{2}{|c|}{ Performance indexes } \\
\hline $\mathrm{Pl}_{\mathrm{ABS}}$ & $(\mathrm{RC} / \mathrm{ABS}) *\left[\phi_{\mathrm{Po}} /\left(1-\phi_{\mathrm{PO}}\right)\right] *\left[\varphi_{\mathrm{o}} /\left(1-\varphi_{\mathrm{o}}\right)\right]$ \\
\hline $\mathrm{Pl}_{\mathrm{CSO}}$ & $\left(\mathrm{ABS} / \mathrm{CS}_{0}\right) *\left[\phi_{\mathrm{PO}} /\left(1-\phi_{\mathrm{Po}}\right)\right] *\left[\varphi_{\mathrm{o}} /\left(1-\varphi_{\mathrm{o}}\right)\right]$ \\
\hline $\mathrm{Pl}_{\mathrm{CSm}}$ & $\left(\mathrm{ABS} / \mathrm{CS}_{\mathrm{M}}\right) *\left[\phi_{\mathrm{PO}} /\left(1-\phi_{\mathrm{PO}}\right)\right] *\left[\varphi_{\mathrm{O}} /\left(1-\varphi_{\mathrm{o}}\right)\right]$ \\
\hline
\end{tabular}


the absorption energy flux per excited cross-section of leaf sample (ABS/CS) in arbitrary units of a particular leaf sample in the dark-adapted state, phenomenological fluxes were estimated from both $F_{0}$ and $F_{M}$, respectively (Table 1 ). The specific and phenomenological fluxes are interrelated by the quantum efficiencies, which are (1) the maximum quantum yield of primary photochemistry $\left(\mathrm{F}_{\mathrm{V}} / \mathrm{F}_{\mathrm{M}}\right)$ which in this terminology is equal to the efficiency by which an absorbed photon will be trapped by the PSII RC with the resultant reduction of $\mathrm{Q}_{\mathrm{A}}$ to $\mathrm{Q}_{\mathrm{A}}{ }^{-}$(TR $\mathrm{T} / \mathrm{ABS}$ ); and (2) the efficiency by which a trapped exciton, having triggered the reduction of $\mathrm{Q}_{\mathrm{A}}$ to $\mathrm{Q}_{\mathrm{A}}{ }^{-}$can move an electron further than $\mathrm{Q}_{\mathrm{A}}{ }^{-}$into the intersystem electron transport chain $\left(\mathrm{ET}_{0} / \mathrm{TR}_{0}\right)$ (Table 1). Integrative parameters, so called performance indexes reflecting performance of the overall energy flow processing are (1) based on quantum efficiencies and hereby related to the situation of assuming equal absorption $\left(\mathrm{PI}_{\mathrm{ABS}}\right)$; and (2) based on the phenomenological fluxes related to the per cross-section level ( $\mathrm{PI}_{\mathrm{CSo}}$ and $\mathrm{PI}_{\mathrm{CSm}}$ ) (Table 1). Estimation of the density of active PSII reaction centres per cross-section (RS/CS $S_{0}$ And $\mathrm{RC} / \mathrm{CS}_{\mathrm{M}}$ ) is also possible. See Table 1 for a full summary of all parameters, formulae, definition of symbols and Fig. 8 for pipeline models depicting the stepwise energy flow through PSII. Brief parameter descriptions are given in the results section the first time a parameter occur (see bellow). Although rich in information, the interpretation of JIP test parameters describing the quantitative behaviour of the PSII must be done carefully, due to both the biophysical and derived nature of these parameters.

\section{Leaves}

After the last measurements all leaves were harvested in order to determine biomass, leaf area, and the content of flavonoids, C, and N. Soil samples were analysed for $\mathrm{C}, \mathrm{N}$, and water content. Immediately after the end harvest of the season on 20 August 2002, digital photographs were taken of all the filter-covered leaves beside a brick of known area. The photographs were loaded in a pixel counting program (Bitmap, S. Danbæk, Biological Institute, University of Copenhagen) and the leaf areas were determined. The dry weight was determined after oven drying for $48-62 \mathrm{~h}$ at $80^{\circ} \mathrm{C}$.

Total soluble flavonoids were extracted by a three step procedure. First, the pulverized leaves were heated $\left(60^{\circ} \mathrm{C}\right)$ in $5 \mathrm{ml}$ methanol for $3 \mathrm{~min}$; second, after adding $5 \mathrm{ml} \mathrm{HCl}-\mathrm{H}_{2} \mathrm{O}-$ methanol $(1: 20: 79)$, leaves were shaken for $10 \mathrm{~min}$; third, the supernatant was diluted 10 fold in $\mathrm{HCl}-\mathrm{H}_{2} \mathrm{O}-$ methanol $(1: 20: 179)$ after centrifugation at approximately $3 \mathrm{~g}$ for $10 \mathrm{~min}$ (Caldwell 1968). After additional 10 min shaking, the UV-absorption was measured with a spectrophotometer (U-2010; Hitachi, Tokyo, Japan) from 280 to $315 \mathrm{~nm}$ at $0.2 \mathrm{~nm}$ intervals. The area below the absorption curve was calculated as the sum of all absorptions in the scanned range. Further, total $\mathrm{C}$ and $\mathrm{N}$ were determined on a Leco truespec ${ }^{\text {TM. }}$ CN elemental determinator (Leco Corporation, St. Joseph).

\section{Soil}

At the end of the season three soil samples were taken at two depths $(5$ and $10 \mathrm{~cm}$ ). Fresh weight was noted before the samples were oven dried at $80^{\circ} \mathrm{C}$ for $62-86 \mathrm{~h}$, and then at the end dry weights were recorded. Total carbon (using Eltra CS-500, Neuss, Germany) and total nitrogen (using Leco FP-428 nitrogen determinator, Leco Corporation) were measured.

\section{Statistical analysis}

Statistical analyses were conducted using the General Linear Model (GLM) procedure (Statistical Analysis Systems Institute 1999). Levene's test was used to test for homogeneity of variance. Where necessary, parameters were transformed in order to meet the assumptions of ANOVA. Fluorescence variables were tested with a repeated measurement ANOVA, with treatment as factor and day repeated within each plot. This was to take into account that the same experimental unit (the leaves on the same shoot) was measured several times during the season. The treatment effects were tested separately on each day of measurement. Seasonal effect of treatment was tested across all measurements during the season. Furthermore, the daily variation in fluorescence parameters was tested for treatment and time effects with GLM Anova repeated measurements contrast option. Contrast variables were set to the three time levels (0900, 1400 and $1800 \mathrm{~h}$ ) and the contrast level was set to 2 (at 1400 noon). Differences were considered at the $P<0.05$ level. Leaf biomass, specific leaf area (SLA), flavonoid content, $\mathrm{C}, \mathrm{N}$, and $\mathrm{C} / \mathrm{N}$-ratio were tested for effects of treatment by one-way ANOVA. In cases of significant treatment effects, these analyses were followed by tests of treatment differences using Tukey test. All values presented here are nontransformed. The fluctuations in photosynthetic active radiation (PAR), Max PAR, UV-B, and Max UV-B during the whole season were tested for time effects by oneway ANOVA followed by Tukey test. Pearson correlations between PAR, Max PAR, UV-B, and Max UV-B were calculated. 


\section{Results}

\section{Climate}

Irradiance data from the measurement days are included for analysis. Fluctuations in PAR, Max PAR and UV-B during the season did show some periods with different covariance between PAR and UV-B irradiance, but these were not significant (data not shown). After a period with high PAR and UV-B irradiance until 12 July, a gradual decrease was seen in PAR, Max PAR and UV-B throughout the rest of the season; there were also days with very low irradiance: 24 July, 26 July and 9 August (Fig. 1). In general, coinciding high PAR and high UV-B irradiance were observed, each being at its peak around $1400 \mathrm{~h}$ (data not shown). The days (24 and 26 July and 9 August) with very low irradiances were not significantly different, but deviated with respect to Tukey grouping (data not shown). Clear sky conditions with no significant difference between light variables were observed on 1, 6 and 13 August, enabling analysis of daily variation in fluorescence parameters (see below). The averages of irradiance of PAR for these three days were, at $0900 \mathrm{~h}, 255$; at $1400 \mathrm{~h}$, 597; and at $1800 \mathrm{~h}, 399 \mu \mathrm{mol}$ photons $\mathrm{m}^{-2} \mathrm{~s}^{-1}$. The similar averages for UV-B were 0.167, 0.543 and

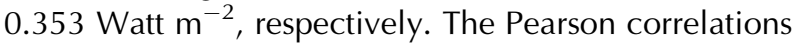
between PAR and UV-B $(n=408)$ were highly significant. In July, the mean air temperature was $6.7^{\circ} \mathrm{C}$ and, in August it was $5.6^{\circ} \mathrm{C}$.

\section{Leaves}

A summary of the statistics on leaf variables shown in Table 2. The leaf biomass and leaf area were lower in ambient UV-B, but not significantly $(P<0.2387$ and $P<0.4866$ ). Furthermore, the higher specific leaf area
(SLA) in ambient UV-B was not significant $(P<0.2238)$. The flavonoid content was significantly higher in ambient UV-B $(P<0.0001)$, while no significant differences were found for $C, N$, and $C / N$ ratio.

\section{Soil}

Samples taken from a depth of $5 \mathrm{~cm}$ had a $24 \%$ mean water content, a mean $\mathrm{C}$ and $\mathrm{N}$ content of 5.4 and $0.25 \%$, and a mean $\mathrm{C} / \mathrm{N}$ ratio of 21.5 . Similarly, the averages in $10 \mathrm{~cm}$ depth had a $23 \%$ mean water content, $\mathrm{C}$ and $\mathrm{N}$ content 3.5 and $0.2 \%$, and a $\mathrm{C} / \mathrm{N}$ ratio of 17.7 .

\section{Chlorophyll a fluorescence}

Seasonal patterns of selected fluorescence variables are shown in Figs 2-7. Significant effects of treatments were seen in July, but these effects disappeared in August Summary statistics of July means of all fluorescence variables can be seen in Table 3, and the summary statistics for the daily variations are shown in Table 4.

After the initial measurement on 6 July, the derived parameters (Strasser et al. 2000, 2004), TR $/$ /ABS (efficiency by which an absorbed photon will be trapped by the PSII reaction centre, $R C$, with the resultant reduction of $\mathrm{Q}_{\mathrm{A}}$ ), $\mathrm{ET}_{0} / \mathrm{TR}_{0}$ (efficiency by which an electron residing on $\mathrm{Q}_{\mathrm{A}}{ }^{-}$will enter the intersystem electron transport chain), and $\mathrm{ET}_{0} / \mathrm{ABS}$ (quantum yield for electron transport), were significantly reduced throughout July in ambient UV-B $(P<0.0041, P<0.0038$, $P<0.0016)$, but from mid-August, the treatment effects disappeared (Table 3, Fig. 2). Quantum efficiencies increased until the season peak on 24 July, and then decreased (Table 3, Fig. 2). The derived specific fluxes (Strasser et al. 2000, 2004) per active PSII reaction

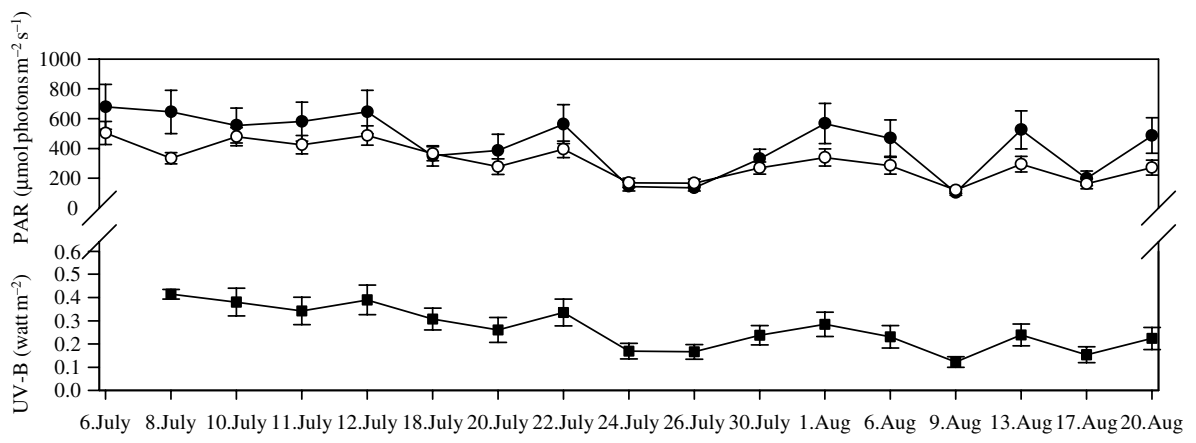

Fig. 1. PAR and maximum PAR (upper) and UV-B (lower). The curves are daily means from the days of measurements, calculated as the hours within the day, and logged by continuously measurements of PAR ( $\mu \mathrm{mol}$ photons $\mathrm{m}^{-2} \mathrm{~s}^{-1}$ ) with one horizontal placed sensor (PAR, depicted as open circles) and a second sloping $45^{\circ}$ facing south (maximum PAR, depicted as closed circles) while UV-B (Watt $\mathrm{m}^{-2}$ ) was continuously logged from a horizontally placed sensor (UV-B, depicted as squares). UV-B data are not available before 8 July 2002. 
Table 2. Measured leaf variables. The numbers are end season means \pm 1 se tested with General linear Model (GLM) one-way ANova followed by Tukey test. Significant effects of treatment are shown by different letters. The resulting values of individual $F$-test and probability of correct null hypothesis are given.

\begin{tabular}{|c|c|c|c|c|c|}
\hline Variable & & Reduced UV-B & Ambient UV-B & Fvalue & ProbF \\
\hline Average leaf biomass & g & $0.032^{A} \pm 0.003$ & $0.026^{A} \pm 0.003$ & 1.43 & 0.2387 \\
\hline SLA & $\mathrm{cm}^{2} \mathrm{~g}^{-1}$ & $8.04^{A} \pm 0.62$ & $10.55^{A} \pm 1.93$ & 1.53 & 0.2238 \\
\hline Flavonoid & arbitrary & $176.85^{B} \pm 0.58$ & $184.84^{\mathrm{A}} \pm 0.57$ & 97.29 & 0.0001 \\
\hline C & $\%$ & $45.14^{\mathrm{A}} \pm 0.23$ & $44.93^{\mathrm{A}} \pm 0.24$ & 0.41 & 0.5273 \\
\hline $\mathrm{N}$ & $\%$ & $1.25^{\mathrm{A}} \pm 0.08$ & $1.35^{A} \pm 0.08$ & 0.87 & 0.3568 \\
\hline $\mathrm{C} / \mathrm{N}$ ratio & ratio & $40.54^{\mathrm{A}} \pm 3.98$ & $36.60^{A} \pm 3.46$ & 0.55 & 0.4517 \\
\hline
\end{tabular}

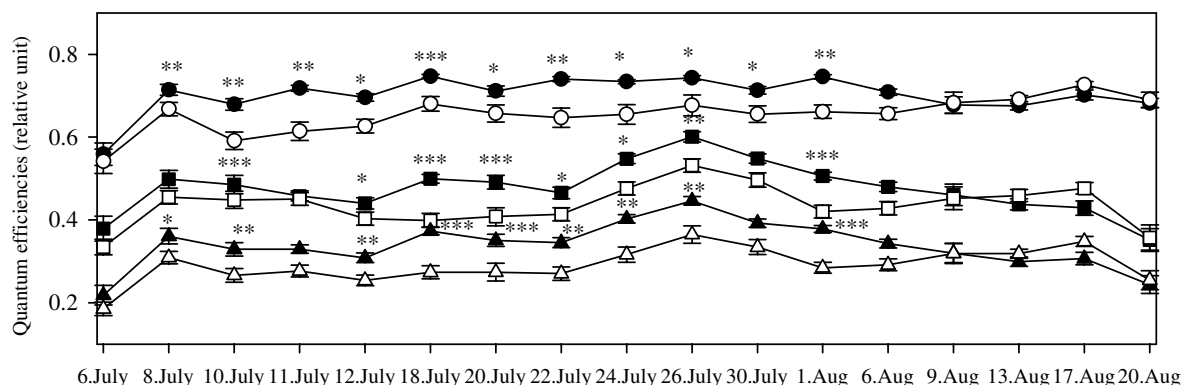

Fig. 2. Quantum efficiencies (ratios between 0 and 1.00). Closed symbols represent reduced UV-B and open symbols ambient UV-B. Curves are daily means \pm SE during the whole season tested with General linear Model (GLM) repeated measurements ANovA $(\alpha=0.05)$. Levels of significance ${ }^{* * *} P<0.0010,{ }^{* *} P<0.0100$, and $* P<0.10$. The efficiency by which an absorbed photon will be trapped by the PSII RC with the resultant reduction of $Q_{A}\left(T R_{0} A B S^{-1}\right)$ is depicted by circles, the efficiency by which an electron residing on $Q_{A}^{-}$will enter the intermediate electron transport chain between PSIl and PSI $\left(\mathrm{ET}_{0} \mathrm{TR}_{0}{ }^{-1}\right)$ is depicted by squares and the quantum yield for electron transport $\left(\mathrm{ET}_{0} \mathrm{ABS}^{-1}\right)$ is depicted as triangles. Across all measurements during season treatment difference were tested and revealed that $\mathrm{TR}_{0} \mathrm{ABS}^{-1}(P<0.0329), \mathrm{ET}_{0} \mathrm{TR}_{0}^{-1}(P<0.1890)$, and ETo $\mathrm{ABS}^{-1}$ $(P<0.0746)$. For meaning of symbols, see Table 1 .

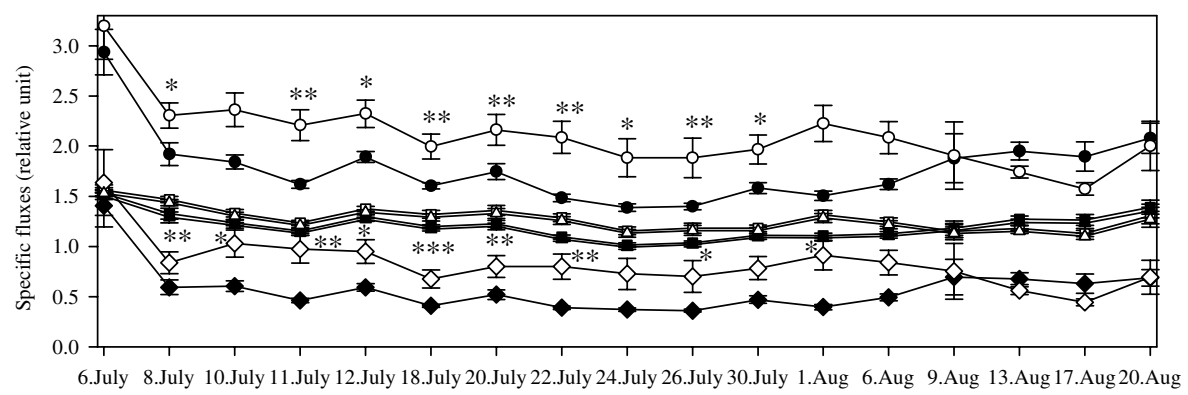

Fig. 3. Specific fluxes per PSII reaction centre (relative unit). Closed symbols represent reduced UV-B and open symbols ambient UV-B. Curves are daily means \pm SE during the whole season tested with GLM repeated measurements ANOVA $(\alpha=0.05)$. Levels of significance $* * * P<0.0010$, ${ }^{* *} P<0.0100$, and $* P<0.10$. Variables are per active PSII RC. Absorption flux of photons $\left(A B S R^{-1}\right)$ is depicted by circles, the maximal trapping $\left(T_{0} R C^{-1}\right)$ is depicted by squares, the electron transport $\left(E T_{0} R C^{-1}\right)$ is depicted as triangles, and the dissipation of untrapped excitons $\left(D_{0} R C^{-1}\right)$ is depicted as diamonds. Across all measurements during season treatment difference were tested and revealed that $A B S R C^{-1}(P<0.0934)$, TR $R C^{-1}$ $(P<0.1367), \mathrm{ET}_{0} \mathrm{RC}^{-1}(P<0.1350)$, and $\mathrm{Dl}_{0} \mathrm{RC}^{-1}(P<0.0978)$. For meaning of symbols, see Table 1 .

centre, RC, $A B S / R C$ (absorption flux of photons per active $R C$ ), $T R_{0} / R C$ (maximum trapping rate by which an exciton is trapped by the PSII RC resulting in the reduction of $\mathrm{Q}_{A}$ ), $\mathrm{DI}_{0} / \mathrm{RC}$ (effective dissipated flux of untrapped excitons per active PSII RC), and $\mathrm{ET}_{0} / \mathrm{RC}$ (electron transport to intersystem chain per active RC) were all significantly higher in July in ambient UV-B $(P<0.0091, \quad P<0.0024, \quad P<0.0153, \quad P<0.0023)$ (Table 3, Fig. 3).

The derived phenomenological fluxes per excited cross-section of leaf sample, estimated from $\mathrm{F}_{0}$, were to some degree affected by treatment. $\mathrm{ABS} / \mathrm{CS}_{0}$ (photons 


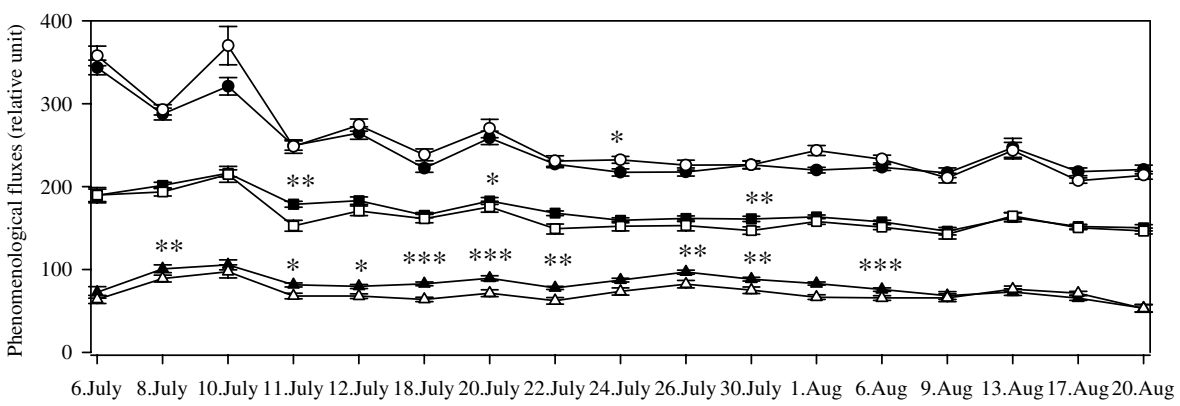

Fig. 4. Phenomenological fluxes per leaf cross-section estimated from $F_{0}$ (relative unit). Closed symbols represent reduced UV-B and open symbols ambient UV-B. Curves are daily means \pm SE error during the whole season tested with GLM repeated measurements ANOVA $(\alpha=0.05)$. Levels of significance ${ }^{* * *} P<0.0010,{ }^{* *} P<0.0100$, and $* P<0.10$. Variables are per cross-section of leaf sample that contains active and inactive PSII RCs. Photons absorbed, at $F_{0}$, by antenna molecules associated with all PSII RCs per cross-section of the sample $\left(A B S C_{0}{ }^{-1}\right.$ ) is depicted by circles, the trapping rate of an exciton that will lead to $\mathrm{Q}_{\mathrm{A}}$ reduction $\left(\mathrm{TR}_{0} \mathrm{CS}_{0}{ }^{-1}\right)$ is depicted by squares, the electron transport as re-oxidation of reduced $\mathrm{Q}_{\mathrm{A}}$ via electron transport $\left(\mathrm{ET}_{0} \mathrm{CS}_{0}^{-1}\right)$ is depicted as triangles. Across all measurements during season treatment difference were tested and revealed that $\mathrm{ABS}$ $\mathrm{CS}_{0}^{-1}(P<0.5153), \mathrm{TR}_{0} \mathrm{CS}_{0}^{-1}(P<0.2121)$, and $\mathrm{ET}_{0} \mathrm{CS}_{0}^{-1}(P<0.0544)$. For meaning of symbols, see Table 1.

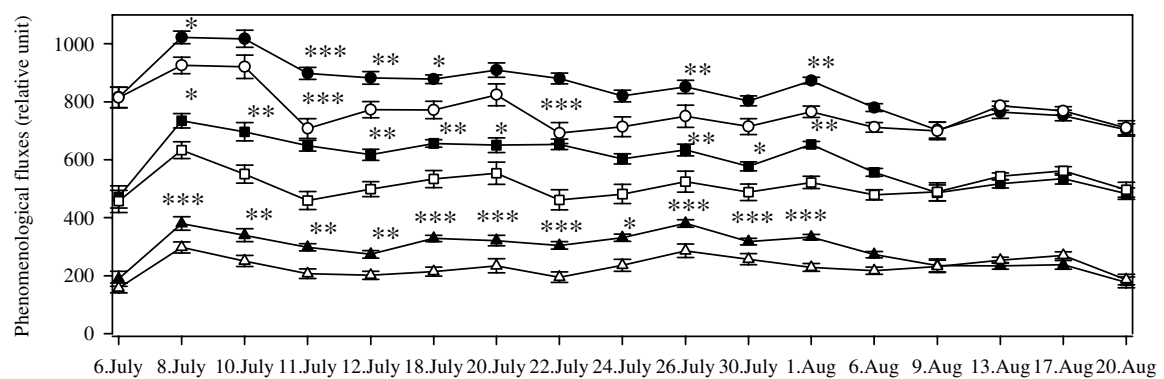

Fig. 5. Phenomenological fluxes per leaf cross-section estimated from $F_{M}$ (relative unit). Closed symbols represent reduced UV-B and open symbols ambient UV-B. Curves are daily means \pm SE during the whole season tested with GLM repeated measurements ANovA $(\alpha=0.05)$. Levels of significance ${ }^{* * *} P<0.0010,{ }^{* * P}<0.0100$, and ${ }^{*} P<0.10$. Variables are per cross-section of leaf sample that contains active and inactive PSII RCs. Photons absorbed, at $F_{M}$, by antenna molecules associated with all PSII RCs per cross-section of the sample $\left(A B S C S_{M}{ }^{-1}\right.$ ) is depicted by circles, the trapping rate of an exciton that will lead to $Q_{A}$ reduction $\left(T_{M} C S_{M}{ }^{-1}\right)$ is depicted by squares, the electron transport as reoxidation of reduced $Q_{A}$ via electron transport $\left(\mathrm{ET}_{\mathrm{M}} \mathrm{CS}_{\mathrm{M}}{ }^{-1}\right)$ is depicted as triangles. Across all measurements during season treatment difference were tested and revealed that ABS $C S_{M}{ }^{-1}(P<0.0124), \mathrm{TR}_{M} C_{M}{ }^{-1}(P<0.0082)$, and $\mathrm{ET}_{\mathrm{M}} \mathrm{CS}_{\mathrm{M}}^{-1}(P<0.0185)$. For meaning of symbols, see Table 1.

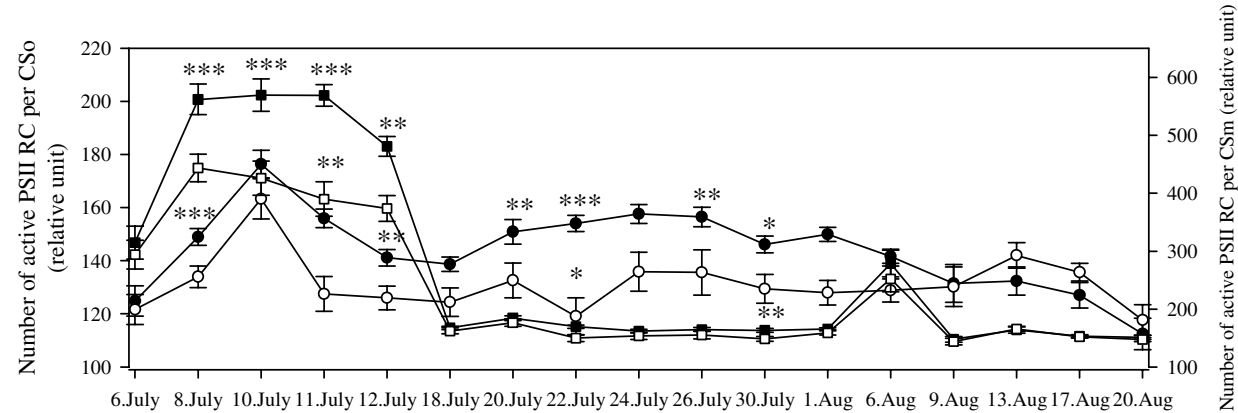

Fig. 6. Number of active PSII reaction centre per cross-section (relative unit). Closed symbols represent reduced UV-B and open symbols ambient UV-B. Curves are daily means \pm SE during the whole season tested with GLM repeated measurements ANOVA $(\alpha=0.05)$. Levels of significance ${ }^{* * *} P<0.0010,{ }^{* *} P<0.0100$, and ${ }^{*} P<0.10$. Number of active PSII RCs estimated from $\mathrm{F}_{0}\left(\mathrm{RC}_{\mathrm{CS}}{ }^{-1}\right)$ depicted as circles and number of active PSII RCs estimated from $F_{M}\left(R C C_{M}{ }^{-1}\right)$ depicted as squares. Across all measurements during season treatment difference were tested and revealed that $\mathrm{RCCS}_{0}^{-1}(P<0.0780)$ and $\mathrm{RC} \mathrm{CS}_{\mathrm{M}}^{-1}(P<0.0191)$. For meaning of symbols, see Table 1. 


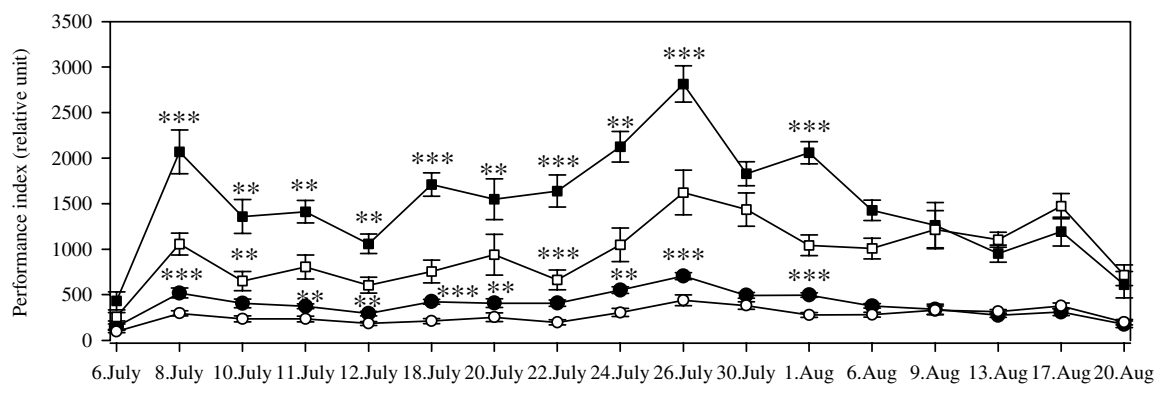

Fig. 7. Performance indexes based per leaf cross-section (relative unit). Closed symbols represent reduced UV-B and open symbols ambient UV-B. Curves are daily means \pm SE during the whole season tested with GLM repeated measurements ANOvA $(\alpha=0.05)$. Levels of significance ${ }^{* * *} P<0.0010,{ }^{* *} P<0.0100$, and ${ }^{*} P<0.10$. Performance index estimated from $\mathrm{M}\left(\mathrm{Pl}_{\mathrm{CSO}}\right)$ depicted as circles and performance index estimated from $\mathrm{M}\left(\mathrm{Pl}_{\mathrm{CSm}}\right)$ depicted as squares. Across all measurements during season treatment difference were tested and revealed that $\mathrm{Pl}_{\mathrm{CSO}}(P<0.0273)$ and $\mathrm{Pl}_{\mathrm{CSm}}(P<0.0192)$. For meaning of symbols, see Table 1.

absorbed, at $\mathrm{F}_{0}$, by antenna molecules associated with all PSII RCs per cross-section of the leaf) tended to increase in ambient UV-B $(P<0.0773)$, but $\mathrm{TR}_{0} / \mathrm{CS}_{0}$ (maximal trapping rate of excitons that will lead to $\mathrm{Q}_{\mathrm{A}}$ reduction per cross-section of the sample) tended to decrease $(P<0.0708)$ (Table 3, Fig. 4). The $\mathrm{ET}_{0} / \mathrm{CS}_{0}$ (maximal electron transport rate per cross-section of sample) was significantly lower in July in ambient UVB $(P<0.0015)$, but in mid-August, the effect of treatment disappeared (Table 3, Fig. 4). Phenomenological fluxes per cross-section of the sample, estimated from $\mathrm{F}_{\mathrm{M}}, \mathrm{ABS} / \mathrm{CS}_{\mathrm{M}}$ (photons absorbed, at $\mathrm{F}_{\mathrm{M}}$, by antenna molecules associated with all PSII RCs per cross-section of the sample), $\mathrm{TR}_{M} / \mathrm{CS}_{M}$ (trapping rate of excitons that will lead to $Q_{A}$ reduction per cross-section of the sample), and $\mathrm{ET}_{M} / \mathrm{CS}_{M}$ (electron transport rate per cross-section of the sample) significantly decreased in July in ambient UV-B $(P<0.0019, P<0.0008$ and $P<0.0003$ ) (Table 3, Fig. 5). Both treatments showed the same seasonal pattern with an increase from the same initial level on 6 July 2002, to two significantly different levels on 8 July (Fig. 5). Hereafter, there was a continuous effect of treatment until 9 August, when the treatment effect disappeared and the phenomenological fluxes decreased to the same low level (Fig. 5).

The estimated number of active PSII reaction centres per sample cross-section using $\mathrm{F}_{0}$ and $\mathrm{F}_{\mathrm{M}}, \mathrm{RC} / \mathrm{CS}_{0}$ and $\mathrm{RC} / \mathrm{CS}_{\mathrm{M}}$, were significantly decreased in July in ambient UV-B $\quad(P<0.0034$ and $P<0.0024) \quad$ (Table 3 and Fig. 6). For both treatments, $\mathrm{RC} / \mathrm{CS}_{0}$ increased from the same initial level to a maximum on 10 July 2002 . Then, the $\mathrm{RC} / \mathrm{CS}_{0}$ significantly decreased in ambient UV-B until 9 August, but then increased to a higher level (Fig. 6). $\mathrm{RC} / \mathrm{CS}_{\mathrm{M}}$ showed more or less the same pattern as $\mathrm{RC} / \mathrm{CS}_{0}$ during the season, but the treatment difference was most pronounced in the beginning of the season, until 18 July (Fig. 6). After 18 July, the RC/CS was reduced to approximately $75 \%$ of the level on 8,10 and 11 July. Hereafter, the $\mathrm{RC} / \mathrm{CS}_{M}$ was marginally higher in ambient UV-B, but after 1 August, there was no effect of treatment (Fig. 6).

The parameters labelled as performance indexes (see Table 1) $\mathrm{Pl}_{\mathrm{CSO}}, \mathrm{Pl}_{\mathrm{CSm}}$, and $\mathrm{PI}_{\mathrm{ABS}}$ were all significantly decreased in ambient UV-B in July $(P<0.0003$, $P<0.0002$ and $P<0.0008$ ) (Table 3). They all showed the same seasonal variation with an increase from the same initial level to a season peak on 26 July 2002 (Fig. 7; curve for $\mathrm{PI}_{\text {Abs }}$ is not shown). Then, there was a simultaneous decrease until 9 August, where the effect of treatment disappears and performance indexes are higher for plants in ambient UV-B (Fig. 7).

The means in July for the yields at the J-I-P steps of the fluorescence transient (Yield $\mathrm{P}_{\mathrm{J}}$, Yield $\mathrm{P}_{\mathrm{I}}$ and Yield $\mathrm{P}_{0}$ ) significantly decreased in ambient UV-B $(P<0.0044$, $P<0.0016$ and $P<0.0041$ ) (Table 3). They all showed the same seasonal pattern with an increase from the initial level, where no treatment difference appeared, to a period with effects of treatment on almost every day of measurements, to a season peak around 26 July 2002. Then the yields decreased and the effects of treatment disappeared after 9 August (data not shown). The ratios of fluorescence values at the J-I-P steps to those of $F_{0}\left(F_{j} / F_{0}, F_{1} / F_{0}\right.$ and $\left.F_{M} / F_{0}\right)$ decreased in ambient UV-B and during July a significant effect of treatment was seen $(P<0.0118, P<0.0012$, and $P<0.0007)$. During the season they showed the same fluctuations as the yields at the J-I-P steps (data not shown). There was no effect of treatment in July on $V_{1}$ (variable fluorescence at step I) and $\mathrm{N}$ (number of $\mathrm{Q}_{\mathrm{A}}$ reduction turnover from time zero to $\left.\mathrm{tF}_{\mathrm{M}}\right)(P<0.1730$ and $P<0.1174)$, but significant effects were seen on $V_{\text {J }}$ (variable fluorescence at J step), Area (area over fluorescence induction curve), $\mathrm{tF}_{M}$ (time to reach $F_{M}$ in $\mathrm{ms}$ ), $M_{0}$ (net rate of PSIl closure, 
Table 3. Measured fluorescence variables. The numbers are July means \pm 1 SE tested with GLM ANovA repeated measurements ( $n=20$ in each treatment and $\alpha=0.05)$. Values of F-test and probability of correct null hypothesis are given.

\begin{tabular}{|c|c|c|c|c|}
\hline & Ambient UV-B & Reduced UV-B & Fvalue & ProbF \\
\hline \multicolumn{5}{|c|}{ Measured parameters } \\
\hline $\mathrm{F}_{0}$ & $263.5 \pm 3.3$ & $251.3 \pm 2.7$ & 3.33 & 0.0773 \\
\hline $\mathrm{F}_{\mathrm{M}}$ & $779.5 \pm 9.8$ & $888.8 \pm 7.0$ & 11.44 & 0.0019 \\
\hline $\mathrm{F}_{50 \mu \mathrm{s}}$ & $279.6 \pm 3.5$ & $267.5 \pm 2.8$ & 3.20 & 0.0831 \\
\hline $\mathrm{F}_{100 \mu \mathrm{s}}$ & $295.0 \pm 3.7$ & $283.1 \pm 3.0$ & 2.77 & 0.1055 \\
\hline$F_{300 \mu s}$ & $355.8 \pm 4.4$ & $347.1 \pm 3.8$ & 1.17 & 0.2873 \\
\hline$F_{J}$ & $547.1 \pm 6.5$ & $570.8 \pm 5.3$ & 1.00 & 0.3243 \\
\hline$F_{1}$ & $647.4 \pm 7.5$ & $711.0 \pm 5.7$ & 6.86 & 0.0134 \\
\hline Area & $20937.3 \pm 594.0$ & $28425.8 \pm 647.7$ & 11.36 & 0.0020 \\
\hline tFm & $618.7 \pm 16.1$ & $699.0 \pm 17.3$ & 7.34 & 0.0107 \\
\hline \multicolumn{5}{|c|}{ Derived parameters } \\
\hline \multicolumn{5}{|c|}{ Selected J-I-P parameters } \\
\hline $\mathrm{F}_{\mathrm{V}}$ & $516.0 \pm 9.2$ & $637.4 \pm 6.6$ & 13.19 & 0.001 \\
\hline $\mathrm{F}_{\mathrm{V}} / \mathrm{F}_{\mathrm{M}}$ & $0.6423 \pm 0.0062$ & $0.7129 \pm 0.0037$ & 9.55 & 0.0041 \\
\hline$V_{J}$ & $0.5621 \pm 0.0056$ & $0.5071 \pm 0.0052$ & 9.75 & 0.0038 \\
\hline$V_{1}$ & $0.7504 \pm 0.0031$ & $0.7227 \pm 0.0032$ & 6.31 & 0.1730 \\
\hline Sm & $39.9 \pm 0.8$ & $44.6 \pm 1.1$ & 4.56 & 0.0404 \\
\hline N & $50.9 \pm 0.9$ & $51.9 \pm 1.2$ & 2.59 & 0.1174 \\
\hline $\mathrm{M}_{0}$ & $0.7539 \pm 0.0138$ & $0.6140 \pm 0.0109$ & 11.26 & 0.0021 \\
\hline Yield $P_{J}$ & $0.1623 \pm 0.0029$ & $0.1985 \pm 0.0027$ & 9.37 & 0.0044 \\
\hline Yield $P_{1}$ & $0.2864 \pm 0.0052$ & $0.3545 \pm 0.0046$ & 11.96 & 0.0016 \\
\hline Yield $P_{0}$ & $0.6424 \pm 0.0062$ & $0.7124 \pm 0.0037$ & 9.55 & 0.0041 \\
\hline$F_{J} / F_{0}$ & $2.106 \pm 0.020$ & $2.299 \pm 0.016$ & 7.14 & 0.0118 \\
\hline$F_{1} / F_{0}$ & $2.515 \pm 0.030$ & $2.887 \pm 0.024$ & 12.57 & 0.0012 \\
\hline $\mathrm{F}_{\mathrm{M}} / \mathrm{F}_{0}$ & $3.042 \pm 0.042$ & $3.625 \pm 0.034$ & 13.98 & 0.0007 \\
\hline \multicolumn{5}{|c|}{ Quantum efficiencies } \\
\hline$\phi_{\mathrm{Po}}=\mathrm{TR}_{0} / \mathrm{ABS}$ & $0.6423 \pm 0.0062$ & $0.7129 \pm 0.0037$ & 9.55 & 0.0041 \\
\hline$\phi_{\mathrm{Eo}}=\mathrm{ET}_{0} / \mathrm{ABS}$ & $0.2864 \pm 0.0052$ & $0.3545 \pm 0.0046$ & 11.96 & 0.0016 \\
\hline $\begin{array}{l}\varphi_{\mathrm{o}}=\mathrm{ET}_{0} / \mathrm{TR}_{0} \\
\text { Specific fluxes }\end{array}$ & $0.4379 \pm 0.0056$ & $0.4929 \pm 0.0052$ & 9.75 & 0.0038 \\
\hline $\mathrm{ABS} / \mathrm{RC}$ & $2.215 \pm 0.054$ & $1.719 \pm 0.029$ & 7.70 & 0.0091 \\
\hline $\mathrm{TR}_{0} / \mathrm{RC}$ & $1.315 \pm 0.013$ & $1.192 \pm 0.011$ & 10.92 & 0.0024 \\
\hline$E T_{0} / \mathrm{RC}$ & $1.287 \pm 0.013$ & $1.166 \pm 0.011$ & 10.93 & 0.0023 \\
\hline $\mathrm{DI}_{0} / \mathrm{RC}$ & $0.901 \pm 0.045$ & $0.528 \pm 0.020$ & 6.57 & 0.0153 \\
\hline \multicolumn{5}{|c|}{ Phenomenological fluxes } \\
\hline $\mathrm{ABS} / \mathrm{CS}_{0}$ & $263.5 \pm 3.3$ & $251.3 \pm 2.7$ & 3.33 & 0.0773 \\
\hline $\mathrm{TR}_{0} / \mathrm{CS}_{0}$ & $166.6 \pm 2.0$ & $176.7 \pm 1.4$ & 3.49 & 0.0708 \\
\hline $\mathrm{ET}_{0} / \mathrm{CS}_{0}$ & $72.3 \pm 1.3$ & $86.6 \pm 1.1$ & 12.12 & 0.0015 \\
\hline $\mathrm{Dl}_{0} / \mathrm{CS}_{0}$ & $96.9 \pm 2.6$ & $74.6 \pm 1.8$ & 9.03 & 0.0051 \\
\hline $\mathrm{ABS} / \mathrm{CS}_{\mathrm{M}}$ & $779.5 \pm 9.8$ & $888.8 \pm 7.0$ & 11.44 & 0.0019 \\
\hline $\mathrm{TR}_{\mathrm{M}} / \mathrm{CS}_{\mathrm{M}}$ & $516.0 \pm 9.2$ & $637.4 \pm 6.6$ & 13.76 & 0.0008 \\
\hline$E T_{M} / C_{M}$ & $232.4 \pm 5.6$ & $318.0 \pm 5.1$ & 16.95 & 0.0003 \\
\hline $\mathrm{DI}_{\mathrm{M}} / \mathrm{CS}_{\mathrm{M}}$ & $263.5 \pm 3.3$ & $251.3 \pm 2.7$ & 3.78 & 0.0608 \\
\hline \multicolumn{5}{|c|}{ Density of PSII reaction centres } \\
\hline $\mathrm{RC} / \mathrm{CS}_{0}$ & $130.6 \pm 1.8$ & $149.6 \pm 1.2$ & 10.00 & 0.0034 \\
\hline $\mathrm{RC} / \mathrm{CS}_{\mathrm{M}}$ & $261.7 \pm 8.4$ & $321.2 \pm 10.6$ & 10.89 & 0.0024 \\
\hline \multicolumn{5}{|c|}{ Performance indexes } \\
\hline $\mathrm{PI}_{\mathrm{ABS}}$ & $1.11 \pm 0.05$ & $1.88 \pm 0.06$ & 13.70 & 0.0008 \\
\hline $\mathrm{Pl}_{\text {CSo }}$ & $264.9 \pm 10.7$ & $438.4 \pm 12.2$ & 16.94 & 0.0003 \\
\hline $\mathrm{Pl}_{\mathrm{CSm}}$ & $938.1 \pm 45.7$ & $1693.8 \pm 54.8$ & 18.35 & 0.0002 \\
\hline
\end{tabular}


Table 4. Measured fluorescence variables. Numbers are daily means \pm 1 sE tested with GLM ANova repeated measurements contrast option $(n=20$ in each treatment and $\alpha=0.05)$. The contrast $P$ statistics is given for each variable. Only measurements from 1 August and 6 August at 0900,1400 and $1800 \mathrm{~h}$ are included.

\begin{tabular}{|c|c|c|c|c|c|}
\hline & 0900 & 1400 & 1800 & $\begin{array}{l}\text { Contrast } \\
0900-1400\end{array}$ & $\begin{array}{l}\text { Contrast } \\
1400-1800\end{array}$ \\
\hline \multicolumn{6}{|c|}{ Measured parameters } \\
\hline $\mathrm{F}_{0}$ & $237.0 \pm 3.3$ & $223.1 \pm 3.0$ & $244.5 \pm 7.6$ & 0.0002 & 0.0147 \\
\hline $\mathrm{F}_{\mathrm{M}}$ & $802.1 \pm 11.2$ & $742.0 \pm 12.0$ & $796.3 \pm 13.7$ & 0.00001 & 0.00001 \\
\hline $\mathrm{F}_{50 \mu \mathrm{s}}$ & $252.5 \pm 3.5$ & $237.8 \pm 3.2$ & $258.2 \pm 7.7$ & 0.0002 & 0.0210 \\
\hline$F_{100 \mu s}$ & $267.0 \pm 3.9$ & $251.8 \pm 3.4$ & $270.9 \pm 7.8$ & 0.0004 & 0.0340 \\
\hline $\mathrm{F}_{300 \mu \mathrm{s}}$ & $327.3 \pm 5.0$ & $309.5 \pm 4.4$ & $326.0 \pm 8.2$ & 0.0009 & 0.0751 \\
\hline$F_{J}$ & $529.5 \pm 6.6$ & $503.6 \pm 7.2$ & $537.6 \pm 8.9$ & 0.0011 & 0.0007 \\
\hline $\mathrm{F}_{1}$ & $653.9 \pm 7.4$ & $615.8 \pm 8.4$ & $679.1 \pm 11.2$ & 0.00001 & 0.00001 \\
\hline Area & $21584.6 \pm 793.1$ & $19715.5 \pm 704.5$ & $25644.8 \pm 1038.2$ & 0.0022 & 0.00001 \\
\hline $\mathrm{tFm}$ & $537.2 \pm 18.3$ & $528.2 \pm 14.6$ & $896.6 \pm 20.1$ & 0.4873 & 0.00001 \\
\hline \multicolumn{6}{|c|}{ Derived parameters } \\
\hline \multicolumn{6}{|c|}{ Selected J-I-P parameters } \\
\hline $\mathrm{F}_{\mathrm{V}}$ & $565.1 \pm 11.8$ & $518.9 \pm 11.7$ & $551.8 \pm 11.9$ & 0.00001 & 0.0008 \\
\hline $\mathrm{F}_{\mathrm{V}} / \mathrm{F}_{\mathrm{M}}$ & $0.6942 \pm 0.0083$ & $0.6880 \pm 0.0078$ & $0.6880 \pm 0.0089$ & 0.2611 & 0.9613 \\
\hline$V_{J}$ & $0.5323 \pm 0.0101$ & $0.5568 \pm 0.0096$ & $0.5455 \pm 0.0100$ & 0.0030 & 0.2126 \\
\hline$V_{1}$ & $0.7458 \pm 0.0062$ & $0.7671 \pm 0.0059$ & $0.7945 \pm 0.0064$ & 0.00001 & 0.00001 \\
\hline Sm & $37.3 \pm 1.0$ & $36.9 \pm 0.09$ & $44.9 \pm 1.2$ & 0.508 & 0.00001 \\
\hline $\mathrm{N}$ & $44.6 \pm 0.9$ & $44.5 \pm 0.8$ & $49.1 \pm 1.3$ & 0.7619 & 0.0002 \\
\hline $\mathrm{M}_{0}$ & $0.6848 \pm 0.0275$ & $0.7097 \pm 0.0236$ & $0.6388 \pm 0.0280$ & 0.128 & 0.0044 \\
\hline Yield $P_{J}$ & $0.1788 \pm 0.0053$ & $0.1634 \pm 0.0051$ & $0.1436 \pm 0.0050$ & 0.005 & 0.4643 \\
\hline Yield $\mathrm{P}_{\mathrm{I}}$ & $0.3304 \pm 0.0092$ & $0.3111 \pm 0.0086$ & $0.3168 \pm 0.0084$ & 0.0001 & 0.0001 \\
\hline Yield $\mathrm{P}_{0}$ & $0.6942 \pm 0.0083$ & $0.6880 \pm 0.0078$ & $0.6880 \pm 0.0089$ & 0.2631 & 0.9599 \\
\hline$F_{j} / F_{0}$ & $2.254 \pm 0.025$ & $2.270 \pm 0.026$ & $2.295 \pm 0.037$ & 0.7525 & 0.4836 \\
\hline$F_{1} / F_{0}$ & $2.805 \pm 0.041$ & $2.791 \pm 0.041$ & $2.916 \pm 0.055$ & 0.5587 & 0.0292 \\
\hline $\mathrm{F}_{\mathrm{M}} / \mathrm{F}_{0}$ & $3.451 \pm 0.062$ & $3.370 \pm 0.061$ & $3.439 \pm 0.075$ & 0.1063 & 0.3635 \\
\hline \multicolumn{6}{|c|}{ Quantum efficiencies } \\
\hline$\phi_{\mathrm{PO}}=\mathrm{TR}_{0} / \mathrm{ABS}$ & $0.6942 \pm 0.0083$ & $0.6880 \pm 0.0078$ & $0.6880 \pm 0.0089$ & 0.2611 & 0.9613 \\
\hline$\phi_{\mathrm{EO}}=\mathrm{ET}_{0} / \mathrm{ABS}$ & $0.3304 \pm 0.0092$ & $0.3111 \pm 0.0086$ & $0.3168 \pm 0.0084$ & 0.005 & 0.4643 \\
\hline$\varphi_{\mathrm{o}}=\mathrm{ET}_{0} / \mathrm{TR}_{0}$ & $0.4677 \pm 0.0101$ & $0.4432 \pm 0.0096$ & $0.4545 \pm 0.0100$ & 0.003 & 0.2126 \\
\hline \multicolumn{6}{|l|}{ Specific fluxes } \\
\hline $\mathrm{ABS} / \mathrm{RC}$ & $1.905 \pm 0.084$ & $1.898 \pm 0.073$ & $1.762 \pm 0.088$ & 0.8419 & 0.093 \\
\hline $\mathrm{TR}_{0} / \mathrm{RC}$ & $1.245 \pm 0.025$ & $1.245 \pm 0.021$ & $1.135 \pm 0.026$ & 0.7245 & 0.00001 \\
\hline $\mathrm{ET}_{0} / \mathrm{RC}$ & $1.215 \pm 0.024$ & $1.216 \pm 0.020$ & $1.110 \pm 0.025$ & 0.7376 & 0.00001 \\
\hline $\mathrm{DI}_{0} / \mathrm{RC}$ & $0.661 \pm 0.065$ & $0.653 \pm 0.057$ & $0.628 \pm 0.065$ & 0.9054 & 0.6287 \\
\hline \multicolumn{6}{|c|}{ Phenomenological fluxes } \\
\hline $\mathrm{ABS} / \mathrm{CS}_{0}$ & $237.0 \pm 3.3$ & $223.1 \pm 3.0$ & $244.5 \pm 7.6$ & 0.0002 & 0.0147 \\
\hline $\mathrm{TR}_{0} / \mathrm{CS}_{0}$ & $162.7 \pm 1.9$ & $152.6 \pm 2.1$ & $163.0 \pm 3.4$ & 0.00001 & 0.0059 \\
\hline $\mathrm{ET}_{0} / \mathrm{CS}_{0}$ & $74.3 \pm 2.9$ & $70.6 \pm 2.3$ & $75.3 \pm 2.7$ & 0.00001 & 0.0054 \\
\hline $\mathrm{DI}_{0} / \mathrm{CS}_{0}$ & $76.3 \pm 1.9$ & $68.2 \pm 1.7$ & $81.4 \pm 5.0$ & 0.184 & 0.0512 \\
\hline $\mathrm{ABS} / \mathrm{CS}_{\mathrm{M}}$ & $802.1 \pm 11.2$ & $742.0 \pm 12.0$ & $796.3 \pm 13.7$ & 0.00001 & 0.00001 \\
\hline $\mathrm{TR}_{\mathrm{M}} / \mathrm{CS}_{\mathrm{M}}$ & $565.1 \pm 11.8$ & $518.9 \pm 11.7$ & $551.8 \pm 11.9$ & 0.00001 & 0.0008 \\
\hline $\mathrm{ET}_{\mathrm{M}} / \mathrm{CS}_{\mathrm{M}}$ & $237.0 \pm 3.3$ & $223.1 \pm 3.0$ & $258.7 \pm 8.7$ & 0.00001 & 0.0039 \\
\hline $\mathrm{DI}_{\mathrm{M}} / \mathrm{CS}_{\mathrm{M}}$ & $272.6 \pm 9.3$ & $238.4 \pm 8.3$ & $244.5 \pm 7.6$ & 0.0002 & 0.0147 \\
\hline \multicolumn{6}{|c|}{ Density of PSII reaction centres } \\
\hline $\mathrm{RC} / \mathrm{CS}_{0}$ & $135.3 \pm 2.5$ & $126.4 \pm 2.5$ & $149.6 \pm 3.6$ & 0.00001 & 0.00001 \\
\hline $\mathrm{RC} / \mathrm{CS}_{\mathrm{M}}$ & $164.3 \pm 1.9$ & $153.9 \pm 2.1$ & $275.4 \pm 15.8$ & 0.00001 & 0.00001 \\
\hline \multicolumn{6}{|c|}{ Performance indexes } \\
\hline $\mathrm{Pl}_{A B S}$ & $1.62 \pm 0.10$ & $1.38 \pm 0.08$ & $1.64 \pm 0.11$ & 0.0034 & 0.0102 \\
\hline $\mathrm{Pl}_{\text {CSO }}$ & $362.3 \pm 19.9$ & $292.6 \pm 16.3$ & $359.9 \pm 19.7$ & 0.00001 & 0.00001 \\
\hline $\mathrm{Pl}_{\mathrm{CSm}}$ & $1369.2 \pm 85.4$ & $1080.0 \pm 70.1$ & $1361.7 \pm 93.2$ & 0.0002 & 0.0008 \\
\hline
\end{tabular}


calculated from the initial slope of the fluorescence induction curve), and Sm (normalized complementary area, normalized for quantitatively comparization of different samples $) \quad(P<0.0038, \quad P<0.0020$, $P<0.0107, P<0.0021$ and $P<0.0404$ ) (Table 3). In late August, the fluctuation between the parameters was shifted and the effects of treatment disappeared (data not shown). There was a close positive relation between Area and $\mathrm{tF}_{\mathrm{M}}$ (data not shown) and a close negative relation between $\mathrm{Sm}$ and $\mathrm{M}_{0}$ (data not shown) during the season.

Data from 1, 6 and 13 August 2002, were pooled and the daily variations in fluorescence variables were tested for time and treatment effects (Table 4). There were no significant effects due to treatment (data not shown). The time effects are shown as the difference between 0900 and $1400 \mathrm{~h}$ (midday) and the difference between 1400 and $1800 \mathrm{~h}$ (afternoon). The quantum efficiencies $\mathrm{ET}_{0} / \mathrm{ABS}$ and $\mathrm{ET}_{0} / \mathrm{TR}_{0}$ decreased at midday, but $\mathrm{TR}_{0} / \mathrm{ABS}$ was unaffected. In the afternoon, the quantum efficiencies were unaffected. The estimated number of PSII RCs (RC/CS $S_{0}$ and $\mathrm{RC} / \mathrm{CS}_{\mathrm{M}}$ ) was significantly lowered at midday and increased in the afternoon. The specific fluxes per PSII RC were not significantly affected at midday, but significant decreases were observed in the afternoon for $A B S / R C$, $\mathrm{TR}_{0} / \mathrm{RC}$, and $\mathrm{ET}_{0} / \mathrm{RC}$. The daily variation in all phenomenological fluxes shows significant midday depression, and a tendency to increased fluxes is seen in the afternoon for the phenomenological fluxes estimated from $F_{M}$, while the opposite is seen for the fluxes estimated from $F_{0}$ (Table 4). The performance index based on equal absorption $\left(\mathrm{Pl}_{\mathrm{Abs}}\right)$ showed a decrease around midday and an increase during the afternoon. This was also found for the performance indexes per cross-section of the samples, using $\mathrm{F}_{0}$ and $\mathrm{F}_{\mathrm{M}}, \mathrm{PI}_{\mathrm{CSo}}$ and $\mathrm{Pl}_{\mathrm{CSm}}$. The fluorescence intensities at $0.05 \mathrm{~ms}$ $\left(F_{50 \mu s}\right)$, at $0.1 \mathrm{~ms}\left(F_{100 \mu s}\right)$, at $0.3 \mathrm{~ms}\left(F_{300 \mu \mathrm{s}}\right)$, at $2 \mathrm{~ms}$ $\left(F_{j}\right)$, and at $30 \mathrm{~ms}\left(\mathrm{~F}_{1}\right)$ all showed decreased values at midday followed by an increase in the afternoon. Finally, the Area (over the fluorescence curve) was significantly decreased at midday and increased in the afternoon. An afternoon increase was also seen for $\mathrm{tF}_{\mathrm{M}}, \mathrm{Sm}$, and $\mathrm{N}$.

\section{Discussion}

In our experiments plants were exposed to simultaneous high ambient PAR and UV-B irradiance. There was a high correlation of PAR and UV-B $\left(r_{\mathrm{s}}=0.79\right)$ and the measurements were conducted at the time of maximum irradiance of PAR and UV-B around $1400 \mathrm{~h}$, the time of the maximal light stress.

\section{Daily variation in chlorophyll a fluorescence parameters}

The daily variations in most fluorescence parameters had a pattern with midday depression at noon. The marked reduction in performance indexes $\left(\mathrm{Pl}_{\mathrm{CSo}}\right.$ and $\left.\mathrm{Pl}_{\mathrm{CSm}}\right)$ sums up the effects of the high midday light values on the phenomenological fluxes (at the level of per crosssection of the sample) (Table 4). The coinciding pattern on phenomenological fluxes derived from $F_{0}$ and $F_{M}$, shows midday decreases in the total number of photons absorbed by the antenna molecule associated with all PSII RCs per cross-section of the sample $\left(\mathrm{ABS} / \mathrm{CS}_{\mathrm{M}}\right)$, the trapping rate of excitons, which leads to reduction of $\mathrm{Q}_{\mathrm{A}}$ $\left(\mathrm{TR}_{\mathrm{M}} / \mathrm{CS}_{\mathrm{M}}\right)$, and the decreased dissipation of photons $\left(\mathrm{DI}_{M} / \mathrm{CS}_{M}\right)$ (Table 4). This leads to decreased electron transport, estimated as reoxidation of $\mathrm{Q}_{\mathrm{A}}{ }^{-}$, over the leaf cross-section of the sample $\left(\mathrm{ET}_{\mathrm{M}} / \mathrm{CS}_{\mathrm{M}}\right)$, at midday (Table 4). Moving on to the specific fluxes (at the level per PSII RC) the impact of high midday PAR and UV-B appears to be low (see below). On the other hand the performance index related to the specific fluxes $\left(\mathrm{Pl}_{\mathrm{Abs}}\right)$ is decreased, indicating midday depression at noon (Table 4). These findings indicate that interpretation of performance indexes $\left(\mathrm{Pl}_{\mathrm{CSo}}, \mathrm{Pl}_{\mathrm{CSm}}\right.$ and $\left.\mathrm{Pl}_{\mathrm{Abs}}\right)$ must be done with care, but also that important differences may appear when integrating the overall response at the levels of phenomenological and specific fluxes.

Interpretation of the relation between phenomenological and specific fluxes may be done in two ways by (1) combining the fact of the decreased estimated density of active PSII RCs $\left(\mathrm{RC} / \mathrm{CS}_{0}\right.$ and $\left.\mathrm{RC} / \mathrm{CS}_{\mathrm{M}}\right)$ with the fact that specific fluxes $\left(\mathrm{ABS} / \mathrm{RC}, \mathrm{TR}_{0} / \mathrm{RC}, \mathrm{DI}_{0} / \mathrm{RC}\right.$ and $\left.\mathrm{ET}_{0} / \mathrm{RC}\right)$ are only mildly affected at midday, or (2) combining the fact of decreased quantum efficiencies $\left(\varphi_{P_{\mathrm{Po}}}\right.$ and $\psi_{\mathrm{o}}$ ) with the fact that initial and maximal fluorescence intensities $\left(F_{0}\right.$ and $\left.F_{M}\right)$ were also decreased (Table 4). Either way, this resulted in decreased phenomenological fluxes.

Both interpretations are reasonable from a theoretical point of view. Thus, the first interpretation (1) deduces phenomenological fluxes from the calculation of specific fluxes per RC (Strasser and Strasser 1995, Strasser et al. 2004) and the integration of the concentration of active RCs per excited cross-section of the sample (RC/ CS) (Strasser et al. 2004) by assuming the absorption of photons per sample cross-section (ABS/CS) can be approximated from the fluorescence intensities $F_{0}$ and $F_{M}$ (Strasser and Strasser 1995, Strasser et al. 2004). On the other hand, in the second interpretation (2) phenomenological fluxes rely on purely the mathematical derived quantum efficiencies and the approximation of ABS/CS (see above and Table 1). 
Now, if it is assumed that the absorption of photons per cross-section of the sample (ABS/CS) does not change during day, then the fluctuations in either specific fluxes or quantum efficiencies will determine the fluctuations in phenomenological fluxes. In this sense, a midday depression in the phenomenological fluxes can be expected when decreases in, for example, $T R_{0} / R C$ (maximal trapping rate of excitons per active PSII RC) or maximum quantum yield of primary photochemistry $\left(\varphi_{\mathrm{Po}}\right)$ are found. Midday depression in phenomenological fluxes may on the other hand also be observed when decreases in $F_{0}$ or $F_{M}$ are measured. In consistence with these assumptions, the only slightly decreased specific fluxes (ABS/RC, $\mathrm{TR}_{0} / \mathrm{RC}, \mathrm{DI}_{0} / \mathrm{RC}$ and $\left.\mathrm{ET}_{0} / \mathrm{RC}\right)$, decreased quantum efficiencies $\left(\varphi_{\mathrm{Po}_{\mathrm{O}}}\right.$ and $\left.\psi_{\mathrm{o}}\right)$ and largely decreased $F_{0}$ and $F_{M}$ (Table 4) led to a pronounced midday depression in phenomenological fluxes.

The behaviour of $F_{M}$ and $F_{0}$ during the day, with a simultaneous decrease seen at midday and in the afternoon, led to a marginally decreased trapping probability $\left(T R_{\mathrm{o}} / \mathrm{ABS}\right)$ at midday and a minor increase in the afternoon. This indicates that the plant optimizes processes related to the trapping. The decreased $F_{0}$ is therefore part of a response that actually leads to a potentially higher or equal trapping amount of photons. This does not appear to be directly reflected in $F_{0}$, when $F_{0}$ is interpreted as a measure of absorption per cross-section $(\mathrm{ABS} / \mathrm{CS})$. These points to precaution before one interpret the $\mathrm{ABS} / \mathrm{CS}_{0}$ per se.

Concerning the quantum efficiencies, they may by indexing to the treatment control be used to relate the degree of stress impact on PSII donor and acceptor side. The PSII donor side related probability, $\mathrm{TR}_{0} / \mathrm{ABS}$ (probability that an absorbed photon will be trapped by the PSII RC with the resultant reduction of $\mathrm{Q}_{\mathrm{A}}$ to $\mathrm{Q}_{\mathrm{A}}{ }^{-}$), was more stable than the PSII acceptor side related probability, $\mathrm{ET}_{0} / \mathrm{TR}_{0}$ (probability an electron residing on $\mathrm{Q}_{\mathrm{A}}{ }^{-}$will enter the intersystem electron transport chain), during the day. This may be interpreted as an indication that the observed midday depression is more related to stress on the acceptor side of PSII than donor side of PSII. In relation to this, then the combination of decreased $\varphi_{\text {Po }}$ measured as $\left(T_{0} / A B S=F_{V} / F_{M}\right)$ and the stability of the maximum trapping flux per PSII RC $\left(\mathrm{TR}_{0} / \mathrm{RC}\right)$ at midday clearly indicates down-regulation by forming-non- $\mathrm{Q}_{\mathrm{A}^{-}}$ reducing RCs, so called heat sink or silent RCs (Strasser and Tsimilli-Micheal 2001, Strasser et al. 2004).

In summary, since the fluctuations of quantum efficiencies, specific fluxes, phenomenological fluxes, density of active PSII RCs, and performance indexes appear to be related to the depression, a controlled plant response to high PAR and UV-B seems to be operating. Further, the clear indication of midday depression as down-regulation by forming-non- $\mathrm{Q}_{\mathrm{A}}$-reducing RCs, socalled heat sink or silent RCs (Strasser and TsimiliMichael 2001), also identify this time of the day to be the time when the plant is potentially most light stressed.

\section{Relation of parameters based on means in July}

The quantum efficiencies $\left(\mathrm{TR}_{0} / \mathrm{ABS}, \mathrm{ET}_{0} / \mathrm{ABS}\right.$, and $\mathrm{ET}_{0} /$ $\mathrm{TR}_{0}$ ) were all clearly decreased in ambient UV-B (Table 3). From Table 3, it can also be seen that the fluxes per PSII RC (ABS/RC, $\mathrm{TR}_{0} / \mathrm{RC}, \mathrm{DI}_{0} / \mathrm{RC}$ and $\mathrm{ET}_{0} /$ $\mathrm{RC})$ were higher in ambient UV-B. The absorption flux of photons per active reaction centre $(A B S / R C)$ was higher in ambient UV-B, but led only to a partly higher maximal trapping rate of excitons per PSII RC ( $\left.T R_{0} / R C\right)$ and electron transport per active PSII RC (ET $/ \mathrm{RC})$. This is probably due to the much higher dissipation flux of untrapped excitons in the active PSII RC $\left(\mathrm{DI}_{0} / \mathrm{RC}\right)$ in ambient UV-B. These relations are depicted in the membrane model in Fig. 8. Integration of these differences per active PSII RC leads to a decrease in the derived parameter $\mathrm{Pl}_{\mathrm{Abs}}$ (performance index based on equal absorption) in ambient UV-B (Table 3), indicating a less effective processing per PSII RC in ambient UV-B. Furthermore, the estimated density of active PSII RCs per cross-section of the sample $\left(\mathrm{RC} / \mathrm{CS}_{0}\right.$ and $\left.\mathrm{RC} / \mathrm{CS}_{\mathrm{M}}\right)$ was decreased in ambient UV-B compared to reduced UV-B (Table 3, Fig. 8). Thus, since the specific fluxes, at the level per $\mathrm{RC}\left(\mathrm{ABS} / \mathrm{RC}, \mathrm{TR}_{0} / \mathrm{RC}, \mathrm{DI}_{0} / \mathrm{RC}\right.$ and $\left.\mathrm{ET}_{0} / \mathrm{RC}\right)$ were increased in ambient UV-B, but the density of PSII RCs per excited cross-section of leaf sample $\left(\mathrm{RC} / \mathrm{CS}_{0}\right.$ and $\mathrm{RC} / \mathrm{CS}_{\mathrm{M}}$ ) was decreased to a larger degree in ambient UV-B, decreases at the per leaf cross-section, phenomenological fluxes $\left(\mathrm{TR}_{0} / \mathrm{CS}_{0}, \mathrm{DI}_{0} / \mathrm{CS}_{0}, \mathrm{ET}_{0} / \mathrm{CS}_{0}, \mathrm{TR}_{\mathrm{M}} /\right.$ $\mathrm{CS}_{M}, \mathrm{DI}_{M} / \mathrm{CS}_{M}$, and $\left.\mathrm{ET}_{M} / \mathrm{CS}_{M}\right)$ were to be expected. In combination, the initial fluorescence intensity $\left(\mathrm{F}_{0}\right)$ increased, maximal fluorescence intensity $\left(F_{M}\right)$ decreased plus quantum efficiencies decreased in ambient UV-B which led to decreased phenomenological fluxes $\left(\mathrm{TR}_{0} / \mathrm{CS}_{0}, \mathrm{DI}_{0} / \mathrm{CS}_{0}, \mathrm{ET}_{0} / \mathrm{CS}_{0}, \mathrm{TR}_{\mathrm{M}} / \mathrm{CS}_{\mathrm{M}}, \mathrm{DI}_{\mathrm{M}} / \mathrm{CS}_{\mathrm{M}}\right.$, and $\mathrm{ET}_{M} / \mathrm{CS}_{M}$ ) in ambient UV-B (Table 3 and pipeline model in Fig. 8). This interpretation on the relations between of specific fluxes, estimated density of PSII $\mathrm{RC}$ per cross-section of leaf sample ( $\mathrm{RC} / \mathrm{CS}_{0}$ and $\mathrm{RC} /$ $\left.C_{M}\right)$, fluorescence intensities $\left(F_{0}\right.$ and $\left.F_{M}\right)$ and quantum efficiencies to phenomenological fluxes is consistent with the one on daily variation (see above).

The behaviour of phenomenological fluxes is summed up in the performance indexes $\mathrm{Pl}_{\mathrm{CS}}$ and $\mathrm{Pl}_{\mathrm{CSm}}$, both being decreased in ambient UV-B (Table 3).

In summary, the concerted decreases found on JIP test parameters, namely phenomenological fluxes, density 


\section{AMBIENT UV-B}

Membrane model

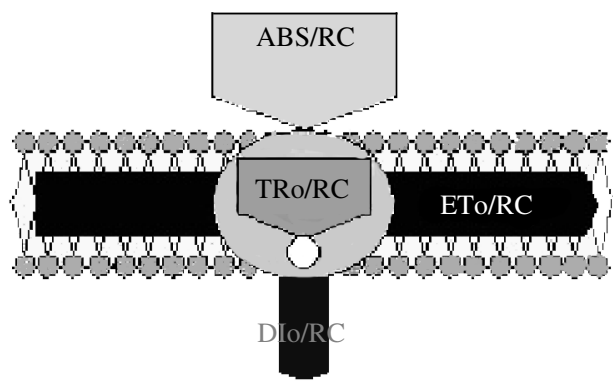

\section{REDUCED UV-B}

Membrane model

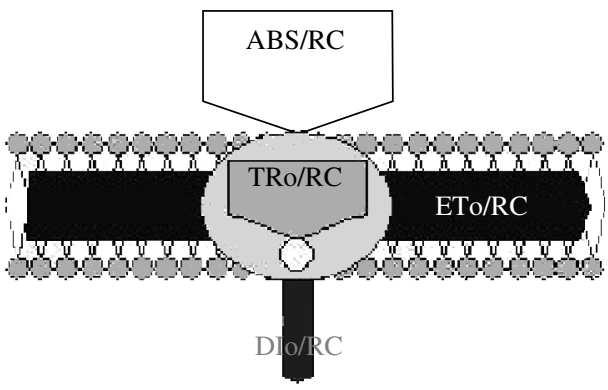

Leaf model

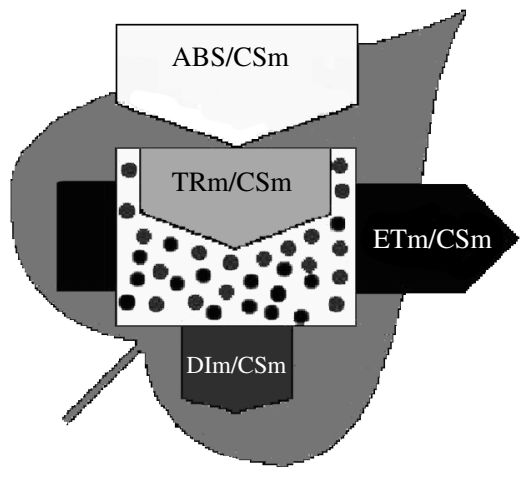

Leaf model

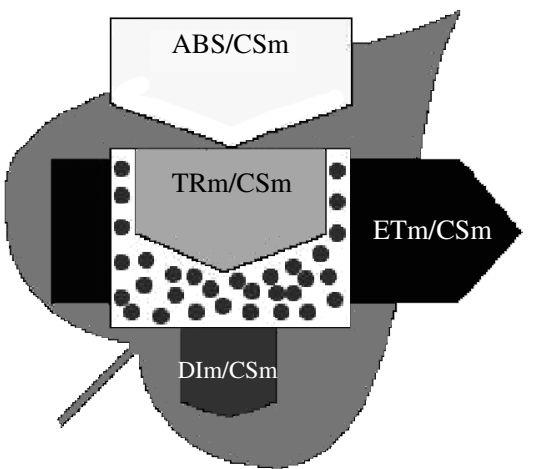

Fig. 8. Pipeline models showing the stepwise flow of energy fluxes in PSII, derived from the fluorescence transient (Table 1), at the level of individual PSII reaction centres (membrane model, displaying the specific fluxes) and at the level of excited leaf sample crosssection (leaf model, displaying phenomenological fluxes). Density of active PSII RCs (depicted as grey circles) and inactive PSII RCS (depicted as black circles) in the leaf model. The models are based on means from July (Table 3). For meaning of symbols, see Table 1. See text for discussions on the relation of fluxes. of active PSII RC, quantum efficiencies and performance indexes in ambient UV-B clearly indicate that ambient UV-B is an important stressor on the photosynthetic apparatus.

\section{Seasonal variation and climate}

The seasonal variation in the fluorescence variables is related to the variation in PAR and UV-B. At the beginning of the season, from 6 to 12 July 2002, an indication of a general build-up of performance of the photosynthetic machinery was seen as a coincident increase in the normalized area over the fluorescence transient $(\mathrm{Sm})$, the area between fluorescence curve and $F_{M}$ (Area), and the time to reach $F_{M}\left(\mathrm{tF}_{\mathrm{M}}\right)$ (data not shown). Furthermore, as a consequence of this, a decreased net rate of PSII closure $\left(M_{0}\right)$ (data not shown), a high level of quantum efficiencies $\left(T R_{0} / A B S\right.$, $\mathrm{ET}_{\mathrm{O}} / \mathrm{TR}_{\mathrm{O}}$ and $\mathrm{ET}_{\mathrm{O}} / \mathrm{ABS}$ ) (Fig. 2), and estimated number of active PSII RCs (RC/CS $S_{0}$ and $\left.R C / C S_{M}\right)$ (Fig. 6) were seen during the same period. After this period of clear sky conditions with high PAR and UV-B (6 to 12 July), the number of PSII RCs $\left(\mathrm{RC} / \mathrm{CS}_{\mathrm{M}}\right)$ was decreased to onefifth, but $\mathrm{RC} / \mathrm{CS}_{0}$ only by $25 \%$ (Fig. 6). Despite this, the general increase in quantum efficiencies $\left(\mathrm{TR}_{0} / \mathrm{ABS}, \mathrm{ET}_{0} /\right.$ $\mathrm{ABS}$, and $\left.\mathrm{ET}_{\mathrm{O}} / \mathrm{ABS}\right)$, phenomenological fluxes $\left(\mathrm{TR}_{\mathrm{O}} / \mathrm{CS}_{\mathrm{O}}\right.$, $\mathrm{DI}_{\mathrm{O}} / \mathrm{CS}_{\mathrm{O}}, \mathrm{ET}_{\mathrm{O}} / \mathrm{CS}_{\mathrm{O}}, \mathrm{TR}_{\mathrm{M}} / \mathrm{CS}_{\mathrm{M}}, \mathrm{DI}_{\mathrm{M}} / \mathrm{CS}_{\mathrm{M}}$, and $\left.\mathrm{ET}_{\mathrm{M}} / \mathrm{CS}_{\mathrm{M}}\right)$, and performance indexes $\left(\mathrm{PI}_{\mathrm{Abs}}, \mathrm{PI}_{\mathrm{CSm}}\right.$, and $\left.\mathrm{PI}_{\mathrm{CSo}}\right)$ continued to increase. All performance indexes and quantum efficiencies had peaks on 24 July and now the opposite response, in comparison to the beginning of the season, is seen in the normalized area over the fluorescence transient $(\mathrm{Sm})$, the area between fluorescence curve and $F_{M}$ (Area), and the time to reach $F_{M}$ $\left(\mathrm{tF}_{\mathrm{M}}\right)$, which all decreased after July 24. Furthermore, the PSII net closure rate $\left(M_{0}\right)$ was increased (data not shown). This coincides with the time when the climatic variables (PAR, UV-B, and air temperature) (Fig. 1, temperature data not shown) were simultaneously decreasing. This decrease continued throughout the season. The 
disappearance of treatment effects after August 9 is in contrast to the phenomena of UV-B promoted senescence (on $F_{V} / F_{M}$ ) found by Zeuthen et al. (2000). In summary, the clear seasonality of the behaviour of fluorescence parameters, derived from the fluorescence transient, clearly indicate the functionality of the JIP test as a sensitive measure of monitoring impacts on the photosynthetic machinery.

\section{UV-B avoidance and biomass}

To avoid the deleterious effects of UV-B, it was expected that the leaves exposed to UV-B would respond by growing thicker and accumulate a higher content of flavonoids as found in other studies (Tevini and Teramura 1989, Bornmann and Vogelmann 1991, Cen and Bornmann 1993, Adamse et al. 1994, Krizek et al. 1994). In this study, Salix leaves did have a higher content of soluble UV-B absorbing compounds in ambient UV-B, indicating accumulation of flavonoids. When no differences in biomass, but higher specific leaf area (SLA) are found it may indicate that leaf thickness is changed. Since this study found no significant difference in leaf biomass and the numeric, but insignificant, higher specific leaf area in ambient UV-B it can not be ruled out that leaf thickness has changed. This response has also been found in some UV-B supplementation experiments on other deciduous plants (Gehrke et al. 1996, Johanson et al. 1995).

Concerning UV-B screening by flavonoids, an unaffected $F_{V} / F_{M}$ ratio $\left(=T R_{0} / A B S\right.$, Table 1$)$ has been suggested as a criterion for successful avoidance of damaging UV-B radiation (Sharma et al. 1998). The significantly reduced $\mathrm{TR}_{0} / \mathrm{ABS}$ in ambient UV-B $(P<0.0329$, Table 3$)$ indicates that the deleterious effect of high UV-B could indeed not be avoided, despite the high content of soluble UV-B absorbing compounds. Therefore direct and indirect effects of ambient UV-B are to be expected further downstream (see below).

Decreased biomass in response to supplemental UV-B has been reported (Tevini and Teramura 1989, Johanson et al. 1995, Searles et al. 1995, Tosserams and Rozema 1995) and Krizek et al. (1997) found a higher biomass in reduced UV-B compared to ambient. In the present study, the leaf biomass was also lowest in ambient UV-B, although not significantly. We speculate that some of the $23 \%$ decrease in leaf biomass may potentially be explained by derived chlorophyll a fluorescence parameters (e.g. $\mathrm{ET}_{0} / \mathrm{ABS}, \mathrm{ET}_{0} / \mathrm{CS}_{0}$ and $\mathrm{ET}_{\mathrm{M}} /$ $\mathrm{CS}_{\mathrm{M}}$ ). Assuming that quantum yield (ETo/ABS) and estimated electron fluxes per cross-section of samples (ETo/ $\mathrm{CS}_{0}$ and $\mathrm{ET}_{\mathrm{M}} / \mathrm{CS}_{\mathrm{M}}$ ) reflect potential proportions of the flux of electrons which lead to $\mathrm{CO}_{2}$ fixation in the Calvin-Benson cycle resulting in biomass allocation for leaf growth. In this context, the decreases in quantum yield ( $\mathrm{ET}_{\mathrm{O}} / \mathrm{ABS}, 15 \%$ decrease in ambient UV-B) and electron transport per cross-section of samples $\left(\mathrm{ET}_{\mathrm{O}} / \mathrm{CS}_{\mathrm{O}}\right.$ and $\mathrm{ET}_{\mathrm{M}} / \mathrm{CS}_{\mathrm{M}}, 13$ and $24 \%$ decrease in ambient UV-B, respectively) may relate to the decreased leaf biomass. In theory, higher respiration during the season or senescence phenomena at the time of harvest could also be a possible explanation for the reduced biomass, but no data in this study can evaluate these possibilities.

Other speculative possibilities may be related to the decreased leaf biomass observed, although not investigated in this study: UV-B induced decreases in photosynthesis by gene regulations (Strid et al. 1990, Jordan et al. 1991, Mackerness et al. 1996) under ecologically relevant conditions have been suggested to be most important (Björn et al. 1999). Furthermore, plants exposed to high levels of PAR and UV-B have been reported to be especially susceptible to formation of active oxygen species (Mazza et al. 1999, Andersson and Aro 2001, Karpinski et al. 2001) and precede downregulation of photosynthesis (Mackernes et al. 1998).

Conducting further parallel measures of the relative quantum efficiency of PSII electron transport $\left(\Phi_{\text {PSII }}\right)$ and by a modulated fluorescence technique (Genty et al. 1989) and parameters derived from the fluorescence transients (e.g. $\mathrm{ET}_{\mathrm{O}} / \mathrm{ABS}, \mathrm{ET}_{\mathrm{O}} / \mathrm{CS}$ and $\mathrm{ET}_{\mathrm{M}} / \mathrm{CS}$ ) may contribute to the further understanding the derived electron flux parameters per cross-section of sample. Moreover, simultaneous measures of leaf gas exchange and modulated fluorescence may potentially identify alternative electron flux (not contributing Calvin-Benson cycle) linked to $\mathrm{O}_{2}$-metabolism as speculated.

\section{Concluding remarks}

The JIP test and associated parameters have been used to study stress effects related to high temperature (Srivastava et al. 1997), low temperature (Van Heerden et al. 2003), high light (Krüger et al. 1997), wind (Clark et al. 2000), nodulation status (Schmitz et al. 2001), but never used in a UV-B exclusion study. The effects of UV-B in exclusion experiments on chlorophyll fluorescence parameters have been studied once by Xiong and Day (2001) in the Antarctic, reporting that UV-B decreased the quantum yield of PSII, measured with modulated chlorophyll a fluorescence.

During the field season 2002, almost all measured and calculated fluorescence parameters indicated that the Salix arctica leaves were less stressed when screened from much of the ambient UV-B by means of filters, compared to leaves exposed to both high PAR 
and high UV-B. Seasonal variation in fluorescence parameters (e.g. $\mathrm{ET}_{0} / \mathrm{ABS}, \mathrm{ET}_{0} / \mathrm{CS}_{0}, \mathrm{ET}_{\mathrm{M}} / \mathrm{CS}_{\mathrm{M}}, \mathrm{RC} / \mathrm{CS}_{0}, \mathrm{RC} /$ $\mathrm{CS}_{\mathrm{M}}, \mathrm{Pl}_{\mathrm{CSo}}, \mathrm{Pl}_{\mathrm{CSm}}$ ) is clearly indicated, but no UV-B promoted senescence on $\mathrm{F}_{\mathrm{V}} / \mathrm{F}_{\mathrm{M}}(=\mathrm{ET} \mathrm{T} / \mathrm{ABS})$ as reported by Zeuthen et al. (2000) was observed.

These findings clearly indicates that ambient UV-B is a stress factor lowering the potential flux of electron per leaf cross-section by decreases in quantum efficiencies and initial and maximal fluorescence. Therefore we conclude that ambient UV-B had negative effects on the photosynthetic apparatus during most of the growth season for the studied plants, with respect to the experimental set-up homogenizing and maximizing the natural light exposure.

Effective dissipated flux of untrapped excitons per active PSII per RC and per cross-section of sample $\left(\mathrm{DI} / \mathrm{RC}, \mathrm{DI}_{0} / \mathrm{CS}_{0}\right.$ and $\left.\mathrm{DI}_{\mathrm{M}} / \mathrm{CS}_{\mathrm{M}}\right)$ was higher in ambient UV-B during July. Furthermore, the daily fluctuations of these parameters clearly indicated a controlled plant response to excess light and UV-B. Therefore, processes related to non-photochemical quenching are probably important for understanding the stress response, but further studies including measurements of modulated fluorescence in combination with pigment content and activity are necessary to evaluate the quenching phenomena (see below). Moreover, for establishment of a causal relationship between the relative quantum efficiency of PSII electron transport $\left(\Phi_{\mathrm{PSII}}\right)$ and consumption of electrons for $\mathrm{CO}_{2}$-fixation in the Calvin-Benson cycle, but also identification of alternative electron sinks (which here may be related to $\mathrm{O}_{2}$-metabolism), simultaneous gas exchange and modulated chlorophyll fluorescence measurements should be conducted. In detail, seen in the light of the debate on general acceptance of derived parameters from the fluorescence transient, focus on studies comparing the general response on fluorescence parameters obtained from fluorescence transients (see Table 1) and from modulated fluorescence is needed. Basic comparison of $F_{0}$ and $F_{M}$ is relevant, but also the so-called electron transport parameters estimated by means of the JIP test $\left(\mathrm{ET}_{0} / \mathrm{RC}, \mathrm{ET}_{0} /\right.$ $\mathrm{CS}_{0}$ and $\left.\mathrm{ET}_{M} / \mathrm{CS}_{M}\right)$ could be compared to the relative quantum efficiency of PSII electron transport $\left(\Phi_{\mathrm{PSIII}}\right)$ derived from modulated fluorescence. Moreover, the estimated energy dissipation parameters $\left(\mathrm{DI}_{0} / \mathrm{RC}, \mathrm{DI}_{0} /\right.$ $\mathrm{CS}_{0}$ and $\left.\mathrm{DI}_{\mathrm{M}} / \mathrm{CS}_{\mathrm{M}}\right)$ could be compared with the nonphotochemical quenching NPQ and its components ( $q_{E}$, $q_{I}$ and $q_{T}$ ). Relation of the results may contribute to such a debate per se, but bearing in mind that only direct measurement on electron transport may be satisfactory.

Concerning the relation of effects on PSII donor and/ or acceptor side capacity, the evaluation of the K-step directly addresses damage on the donor side (Strasser
1997). Further, the relative importance of donor- and acceptor side capacity can also be evaluated by deriving an index of $\mathrm{TR}_{0} / \mathrm{ABS}$ and $\mathrm{ET}_{0} / \mathrm{ABS}$ to treatment as done here.

With respect to the present study, the experimental set-up and the-non-invasive measurements proved to be a sensitive method to screen for effects of UV-B stress.

Acknowledgements - The work was financially supported by DANCEA (Danish Co-operation for Environment in the Arctic). Thanks to the staff from the Danish Polar Center for making the experiments in Zackenberg possible. The authors would like to thank Esben Vedel Nielsen, Gosha Sylvester, Niels Bruun, and Karna Heinsen for help on soil and leaf chemical analyses and Svend Danbæk for valuable help on datalogger set-up and data programming.

\section{References}

Adamse P, Britz SJ, Caldwell CR (1994) Amelioration of UV-B damage under high irradiance. II. Role of blue-light photoreceptors. Photochem Photobiol 60: 110-115

Andersson B, Aro E-M (2001) Photodamage and D1 protein turnover in photosystem II. In: Aro E-M, Andersson B (eds) Regulation of Photosynthesis (Advances in Photosynthesis and Respiration. Kluwer Academic Publishers, Dordrecht, The Netherlands, Vol. 11, pp. 377-393

Asada K (1999) The water-water cycle in chloroplasts: Scavenging of active oxygens and dissipation of excess photons. Annu Rev Plant Physiol Plant Mol Biology 50: 601-639

Bilger W, Björkmann O (1991) Temperature dependence of violaxanthin de-epoxidation and non-photochemical fluorescence quenching in intact leaves of Gossypium hitsutum L. \& Malva parviflora L. Planta 184: 226-234

Björn LO, Callaghan TV, Gehrke C, Gwynn-Jones D, Lee JA, Johanson U, Sonesson M, Buck ND (1999) Effects of ozone depletion an increased ultraviolet-B radiation on northern vegetation. Polar Res 18: 331-337

Böcher TW, Fredskild B, Holmen K, Jacobsen K (1978) Grønlands Flora. P. Haase and Søns Forlag, Copenhagen, Denmark, pp. 132-137

Bornmann JF, Vogelmann TG (1991) Effects of UV-B radiation on leaf optical properties measured with fibre optics. J Exp Bot 42: 547-554

Bredahl L, Ro-Poulsen H, Mikkelsen TN (2004) Reduction of the Ambient UV-B Radiation in the High Arctic increases $\mathrm{Fv} / \mathrm{Fm}$ in Salix arctica and Vaccinium uliginosum and reduces stomatal conductance and internal $\mathrm{CO}_{2}$ concentration in Salix arctica. Arctic, Antarctic Alpine Res 36: 363-368

Caldwell MM (1968) Solar ultraviolet radiation as an ecological factor for alpine plants. Ecol Monographs 39: 243-268 
Caldwell MM, Flint SD (1994) Stratospheric ozone reduction, solar UV-B radiation and terrestrial ecosystems. Climatic Change 28: 375-394

Caldwell MM, Flint SD (1997) Use of biological spectral weighting functions and the need of scaling for the ozone problem. Plant Ecol 128: 66-76

Caldwell MM, Björn LO, Bornman JF, Flint SD, Kulandaivelu G, Teramura AH, Tevini M (1998) Effects on increased solar ultraviolet radiation on terrestrial ecosystems. J Photochem Photobiol B: Biology 46: 40-52

Caldwell MM, Flint SD, Searles PS (1994) Spectral balance and UV-B sensivity of soyabean: a field experiment. Plant, Cell Environ 17: 267-276

Caldwell MM, Robberecht R, Billings WD (1980) A steep latitudinal gradient of solar ultraviolet- $B$ radiation in the arctic-alpine life zone. Ecology 61: 600-611

Cen Y-P, Bornmann JF (1993) The effect of exposure to enhanced UV-B radiation on the penetration of monochromatic and polychromatic UV-B radiation in leaves of Brassica napus. Physiol Plant 87: 249-255

Clark AJ, Landolt W, Bucher JB, Strasser RJ (2000) How wind affects the photosynthetic performance of trees: Quantified with chlorophyll-a fluorescence and open-top chambers. Photosynthetica 38: 349-360.

Cybulski WJ, Peterjohn WT (1999) Effects of ambient UV-B radiation on the aboveground biomass of seven temperatezone plant species. Plant Ecol 145: 175-181.

Day TA, Ruhland CT, Xiong FS (2001) Influence of solar ultraviolet- $B$ radiation on Antarctic terrestrial plants: results from a 4-year field study. J Photochem Photobiol B: Biology 62: 78-87.

Demmig-Adams B, Adams WW III (1994) Light stress and photoprotection related to the xanthophyll cycle. In: Foyer $\mathrm{CH}$, Mullineaux PM (eds) Causes of Photooxidative Stress and Amelioration of Defence Systems in Plants. CRC Press, Boca Raton FL, pp. 105-126

Farman JC, Gardiner BG, Shanklin JD (1985) Large losses of total ozone in Antarctica reveal seasonal Chlorine OxideNitrogen Oxide interaction. Nature 35: 207-210

Flint SD, Ryel RJ, Caldwell MM (2003) Ecosystem UV-B experiments in terrestrial communities: a review of recent findings and methodologies. Agric For Meteor 120: 177-189

Force L, Critchly C, van Rensen JJS (2003) New fluorescence parameters for monitoring photosynthesis in plants. 1. The effect of illumination on the fluorescence parameters of the JIP-test. Photosynthesis Res 78: 17-33

Gehrke C, Johanson U, Björn LO, Callaghan TV, Lee JA (1996) Effects of enhanced ultraviolet-B radiation on terrestrial sub-arctic ecosystems and implications for interactions with increased atmospheric $\mathrm{CO}_{2}$. Ecol Bull 45: 192-203

Genty B, Briantis J-M, Baker NR (1989) The relationship between the quantum yield of photosynthetic electron transport and quenching of chlorophyll fluorescence. Biochim Biophys Acta 990: 87-92
Gwynn-Jones D, Johanson U (1996) Growth and pigment production in tho subarctic grass species under four different UV-B irradiation levels. Physiol Plant 97: 701-707

Gwynn-Jones D, Lee JA, Callaghan TV (1997) Effects of enhanced UV-B radiation and elevated carbon dioxide concentration on sub-arctic forest heath system. Plant Ecol 128: $242-249$

Iwanzik W, Tevini M, Dohnt G, Voss M, Weiss W, Graber Renger G (1983) Action of UV-B radiation on photosynthetic primary reactions in spinach chloroplasts. Physiol Plant 58: 401-407

Jansen MAK, Gaba V, Greenberg BM (1998) Higher plants and UV-B radiation: Balancing damage, repair and acclimation. Trends Plant Sci 3: 131-135

Jansen MAK, Gaba V, Greenberg BM, Mattoo AK, Edelman $M$ (1996) Low threshold levels of ultraviolet-B in a background of photosynthetically active radiation trigger rapid degradation of the D2 protein of photosystem-II. The Plant J 9: 693-699

Johanson U, Gehrke C, Björn LO, Callaghan TV (1995) The effects of enhanced UV-B radiation on the growth of dwarf scrubs in a subarctic heathland. Func Ecol 9: 713-719

Jordan BR, Chow WS, Strid $\AA$, Anderson JM (1991) Reduction in Cab and psA RNA transcipts in response to supplementary UV-B radiation. FEBS Lett 284: 5-8

Karpinski S, Escobar C, Karpinska B, Creissen G, Mullineaux $P$ (1997) Photosynthetic electron transport regulates the expression of cytosolic ascorbate peroxidase genes in Arabidopsis during excess light stress. Plant Cell 9: 642

Karpinski S, Reynolds H, Karpinska B, Wingsle G, Creissen G, Mullineaux P (1999) Systemic signaling and acclimation in response to excess excitation energy in Arabidopsis. Science 284: 654-657

Karpinski S, Wingsle G, Karpinska B, Hällgren J-E (2001) Redox sensing of Photooxidative stress and acclimatory mechanisms in plants. In: Aro, E-M, Andersson, B (eds) Regulation of Photosynthesis (Advances in Photosynthesis and Respiration, Vol. 11). Kluwer Academic Publishers, Dordrecht, The Netherlands, pp 469-486

Krause GH (1994) The role of oxygen in photoinhibition of photosynthesis. In: Foyer $\mathrm{CH}$, Mullineaux, PM (eds) Causes of Photooxidative Stress and Amelioration of Defence Systems in Plants. CRC Press, Boca Raton FL., pp 43-76

Krause GH, Weis E (1991) Chlorophyll fluorescence and photosynthesis: The basics. Annu Rev Plant Physiol Plant Mol Biology 42: 313-349

Krizek DT, Mirecki RM (2004) Evidence for phytotoxic effects of cellulose acetate in UV exclusion studies. Environ Exp Bot 51: 33-43

Krizek PT, Mirecki RM, Britz SJ (1997) Inhibitory effects of ambient levels of solar UV-A and UV-B radiation on a growth of cucumber. Physiol Plant 100: 886-893

Krizek DT, Mirecki RM, Kramer GF (1994) Growth analysis of UV-B irradiated cucumber seedlings as influenced by 
photosynthetic photon flux source and cultivar. Physiol Plant 90: 593-599

Krüger GHJ, Tsimilli-Michael M, Strasser RJ (1997) Light stress provokes plastic and elastic modifications in structure and function of Photosystem II in camellia leaves. Physiol Plant 101: 265-277

Larkum AWD, Karge M, Reifarth F, Eckert H-J, Post A, Renger G (2001) Effect of monochromatic UV-B radiation on electron transfer reactions of Photosystem II.

Photosynth Res 68: 49-60

Lazár D (1999) Chlorophyll a fluorescence induction. Biochim Biophys Acta 1412: 1-28

Mackerness SAH, Butt PJ, Jordan BR, Thomas B (1996) Amelioration of ultraviolet-B-induced down-regulation of mRNA levels for chloroplast proteins by high irradiance is mediated by photosynthesis. J Plant Physiol 148: 100-106

Mackerness SAH, Jordan BR, Thomas B (1997) UV-B effects on the expression of genes encoding proteins involved in photosynthesis. In: Lumsden PJ (ed) Plants and UV-B. Responses to Enviromental Change. Cambridge University Press, Cambridge, UK, pp. 113-134

Mackerness SAH, Surplus SL, Jordan BR, Thomas B (1998) Effects of supplemental ultraviolet-B radiation on photosynthetic transcripts at different stages of leaf development and light levels in pea (Pisum sativum): Role of active oxygen species and antioxidant enzymes. Photochem Photobiol 68: 88-96

Madronich S, McKencie RL, Björn LO, Caldwell MM (1998) Changes in biologically ultraviolet radiation reaching the Earth's surface. J Photochem Photobiol B Biol 46: 5-19

Mazza CA, Battissta D, Zima AM, Scwarcberg-Bracchitta M, Giordano CV, Acevedo A, Scopel AL, Ballaré CL (1999) The effect of solar ultraviolet-B radiation on the growth and yield of barley are accompanied by increased DNA damage and antioxidant responses. Plant, Cell Environ 22: $61-70$

Melis A, Nemson JA, Harrison MA (1992) Damage to functional components and partial degradation of Photosystem II reaction centre proteins upon chloroplast exposure to ultraviolet-B radiation. Biochemica Biophysica Acta 1109: 312-320

Mullineaux P, Ball L, Escobar C, Karpinska B, Creissen G, Karpinski S (2000) Are diverse signaling pathways integrated in the regulation of Arabidopsis antioxidant defence gene expression in response to excess energy. Philosoph Trans Royal Soc London B 355: 1531-1540

Paul N (2001) Plant responses to UV-B: time to look beyond stratospheric ozone depletion? New Phytol 150: 1-8

Paul ND, Gwynn-Jones D (2003) Ecological roles of solar UV-B radiation: towards an integrated approach. Trends Ecol Evol 18: 48-55

Pontailler JY (1990) A cheap quantum sensor using a gallium arsenide photodiode. Func Ecol 4: 591-596

Renger GM, Völker Hj Eckert R, Fromme Holm-Veit S, Graber P (1989) On the mechanism of photosystem II deterioration by UV-B-irradiation. Photochem Photobiol 49: 97-105

Robberecht R, Caldwell MM, Billings WD (1980) Leaf ultraviolet optical properties along a latitudinal gradient in the arctic-alpine lifezone. Ecology 61: 612-619

RobsonT, Pancotto VA, Flint SD, Ballare CL, Sala OE, Scopel AL, Caldwell MM (2003) Six years of solar UV-B manipulations affect growth of Sphagnum and vascular plants in a Tierra del Fuego peatland. New Phytol 160: 379-389

Rousseaux MC, Scopel AL, Searles PS, Caldwell MM, Sala OE, Ballare CL (2001) Responses to solar ultraviolet-B radiation in a shrub-dominated natural ecosystem of Tierra dell Fuego (southern Argentina). Global Change Biol 7: 467-478

Schmitz P, Maldonado-Rodriguez R, Strasser RJ (2001) Evaluation of the nodulated status of Vigna uniculata probed by the JIP-test based on the chlorophyll-a fluorescence rise. In: Proceedings of the 12th International Congress of Photosynthesis, S36-012. CSIRO Publishing, Collingwood, Australia

Searles PS, Caldwell MM, Winther K (1995) The response of five tropical dicotyledon species to solar ultraviolet-B radiation. Am J Bot 82: 445-453

Sharma KP, Anand P, Sankhalkar S, Shetye R (1998) Photochemical and biochemical changes in wheat seedling exposed to supplementary UV-B radiation. Plant Sci 132: $21-30$

Srivastava A, Guissé B, Greppin H, Strasser RJ (1997) Regulation of antenna structure and electron transport in Photosystem II of Pisum sativum under elevated temperature probed by the fast polyphasic chlorophyll a fluorescence transient: OKJIP. Biochim Biophys Acta 1320: 95-106.

Statistical Analysis Systems Institute (1999) SAS/STAT Users guide. Release 8.2. SAS Institute Inc, Cary, NC

Stirbet AD, Srivastava A, Strasser RJ (1998) The energetic connectivity of PSII centers in higher plants probed in vivo by the fast fluorescence rise O-J-I-P and numerical simulations. In: Garab G (ed) Photosynthesis: Mechanisms and Effects. Kluwer Academic Publishers, Dordrecht, The Netherlands, Vol. 5, pp 4317-4320

Strasser BJ (1997) Donor side capacity of Photosystem II probed by chlorophyll-a fluorescence transients.

Photosynth Res 52: 147-155

Strasser BJ, Strasser RJ (1995) Measuring fast fluorescence transients to address environmental questions: The JIP-test. In: Manthis P (ed) Photosynthesis, From Light to Biosphere. Proceedings of the Xth International Photosynthesis Congress, Montpellier-France 1995. Kluwer Academic Publishers, Dordrecht, The Netherlands, Vol. 5, pp 977-980

Strasser RJ, Tsimilli-Micheal M (2001) Stress in plants, from daily rhythm to global changes, detected and quantified by the JIP-Test. Chimie Nouvelle (SRC) 75: 3321-3326 
Strasser RJ, Srivastava A, Govindjee (1995) Polyphasic chlorophyll a fluorescence transients in plants and cyanobacteria. Photochem Photobiol 61: 32-42

Strasser RJ, Tsimilli-Micheal M, Srivastava A (2000) The fluorescence transient as a tool to characterize and screen photosynthetic samples. In: Yunus M, Pathre U, Mohanty P (eds) Probing Photosynthesis: Mechanisms, Regulation and Adaptation. Taylor \& Francis, London, UK, pp 445-483

Strasser RJ, Tsimilli-Micheal M, Srivastava A (2004) Analysis of the chlorophyll a fluorescence transient. In: Papageorgiou GC, Govindjee (eds) Chlorophyll A Fluorescence: A signature of photosynthesis. Advances in photosynthesis and respiration Volume 19. Springer, Berlin, pp 321-362

Strid Å, Chow WS, Anderson JM (1990) Effects of supplementary ultraviolet-B radiation on photosynthesis in Pisum sativum. Biochim Biophys Acta 1020: 260-268

Strid Å, Chow WS, Anderson JM (1996) Temperaturedependency of changes in the relaxation of electrochromic shifts, of chlorophyll fluorescence, and in the levels of mRNA transcripts in detached leaves from Pisum sativum exposed to supplementary UV-B radiation. Plant Sci 115: 199-206

Tevini M, Teramura AH (1989) UV-B effects on terrestrial plants. Photochem Photobiol 50: 479-487

Tosserams M, Rozema J (1995) Effects of ultraviolet-B radiation on growth and physiology of the dune grassland species Calamagrostris epigeios. Environ Bull 89: 209-214

Tsimilli-Michael M, Strasser RJ (2001) Fingerprints of climate changes on the photosynthetic apparatus' behaviour, monitored by the JIP-test. In: Walther G-R, Burga CA,
Edwards PJ (eds) 'Fingerprints' of Climate Changes Adapted Behaviour and Shifting Species Ranges. Kluwer Academic/Plenum Publishers, New York \& London, pp 229-247

Van Heerden PDR, Tsimilli-Michael M, Krüger GHJ, Strasser RJ (2003) Dark chilling effects on soybean genotypes during vegetative development: Parralel studies of $\mathrm{CO}_{2}$ assimilation, chlorophyll a fluorescence kinetics O-J-I-P and nitrogen fixation. Physiol Plant 117: 476-491

Vass I, Kirilovsky D, Etienne AL (1999) UV-B radiationinduced donor- and acceptor side modifications of Photosystem II in the cyanobacterium Synechocystis sp. PCC 6803. Biochemistry 38: 12786-12794

Vass I, Sass L, Spetea C, Bakou A, Ghanothakis F, Petrouleas $\checkmark$ (1996) UV-B induced inhibition of photosystem II electron transport studied by EPR and chlorophyll fluorescence. Impairment of donor and acceptor side components. Biochemistry 35: 8964-8973

Webb AR (1997) Monitoring changes in UV-B radiation. In: Lumsden PJ (ed) Plants and UV-B: Responses to Environmental Change. Cambridge University Press, Cambridge, UK, pp 13-30

Xiong FS, Day TA (2001) Effect of solar ultraviolet-B radiation during springtime ozone depletion on photosynthesis and biomass production of Antarctic vascular plants. Plant Physiol 125: 738-751

Zeuthen J, Mikkelsen TN, Paludan-Müller G, Ro-Poulsen H (2000) Effects of increased UV-B radiation and elevated levelss of troposheric ozone on physiological processes in European beech (Fagus sylvatica) Physiol Plant 100: $281-290$ 